\title{
Wearable Inertial Sensors for Human Movement Analysis
}

\section{Marco losa, Pietro Picerno, Stefano Paolucci \& Giovanni Morone}

To cite this article: Marco losa, Pietro Picerno, Stefano Paolucci \& Giovanni Morone (2016): Wearable Inertial Sensors for Human Movement Analysis, Expert Review of Medical Devices, DOI: 10.1080/17434440.2016.1198694

To link to this article: http://dx.doi.org/10.1080/17434440.2016.1198694

Accepted author version posted online: 16

Jun 2016.

Published online: 16 Jun 2016.

Submit your article to this journal $\sqsubset$

Q View related articles $\square$

View Crossmark data \lceil 
Publisher: Taylor \& Francis

Journal: Expert Review of Medical Devices

DOI: $10.1080 / 17434440.2016 .1198694$

REVIEW

\title{
Wearable Inertial Sensors for Human Movement Analysis
}

\author{
Marco Iosa ${ }^{1}$, Pietro Picerno $^{2}$, Stefano Paolucci $^{1}$, Giovanni Morone $^{1}$ \\ ${ }^{1}$ Clinical Laboratory of Experimental Neurorehabilitation, Fondazione Santa Lucia IRCCS \\ 2 "eCampus" University, Faculty of Psychology, School of Sport and Exercise Sciences, Novedrate \\ (CO), Italy;
}

\section{Corresponding author \\ Marco Iosa \\ email: $\underline{\text { m.iosa@hsantalucia.it }}$ \\ phone: +390651501077 \\ Email of other authors:}

pietro.picerno@gmail.com; g.morone@hsantalucia.it; s.paolucci@hsantalucia.it 


\section{Abstract}

Introduction: The present review aims to provide an overview of the most common uses of wearable inertial sensors in the field of clinical human movement analysis.

Areas covered: Six main areas of application are analysed: gait analysis, stabilometry, instrumented clinical tests, upper body mobility assessment, daily-life activity monitoring and tremor assessment. Each area is analyzed both from a methodological and applicative point of view. The focus on the methodological approaches is meant to provide an idea of the computational complexity behind a variable/parameter/index of interest so that the reader is aware of the reliability of the approach. The focus on the application is meant to provide a practical guide for advising clinicians on how inertial sensors can help them in their clinical practice.

Expert Commentary: Less expensive and more easy to use than other systems used in human movement analysis, wearable sensors have evolved to the point that they can be considered ready for being part of routine clinical routine.

\section{Keywords:}

Accelerometry, gait analysis, kinematics, biomechanics, motor assessment, rehabilitation 


\section{Introduction to human movement analysis}

The instrumented human movement analysis consists in sensor-based measurement techniques aimed to objectively describe and quantitatively assess the motor functions and the motor abilities of a subject $[1,2]$. It is fundamental for assessing pathological conditions, compensatory motor strategies, and for evaluating the improvements during a rehabilitation pathway, in a more sensible and objective manner than the ordinal scores of "semi-quantitative" clinical scales[3]. Through instrumented movement analysis, the kinematic and kinetic parameters of human movements can be determined, and musculoskeletal functions can be quantitatively evaluated. As a result, instrumented movement analysis has been employed in clinical assessment, rehabilitation, sports and even diagnostics.

A standard laboratory of human movement analysis is composed of multi-camera motion capture systems for the measurement of human movement via the kinematics and kinetics of body joints [47]. However, this requires specialized laboratories, expensive equipment, and lengthy set-up and post-processing times, with limitations in terms of measurement volume.

Since the start of the new millennium, technology advances in the field of motion measurement techniques have allowed to measure the kinematics of body segments via wearable inertial sensors such as accelerometers and gyroscopes [8] instead of optoelectronic systems. Potential benefits of wearable inertial devices include: their low cost with respect to the more commonly used gait analysis equipments, their smalldimensions and light weight, and the absence of limitation of the testing environment to a laboratory[8].

The aim of the present review is to provide the reader with an expert (despite non-systematic) overview of the most common uses of wearable inertial sensors in the field of clinical human movement analysis, by focusing both on the methodological approach, and on the clinical application (updated at December 2015). The focus on the methodological approaches is meant to provide an idea of the algorithms behind a variable/parameter/index of interest, and on the validity and reliability of each approach. The focus on the application is meant to provide a practical guide for advising clinicians on how inertial sensors can help them in their clinical practice.

\subsection{Functioning principle of Inertial Sensors}

The term "Inertial sensors" refers to a family of sensors essentially represented by linear acceleration sensors (accelerometers) and angular velocity sensors (gyroscopes). The term "inertial" refers to the fact that these sensors measure their own movement (and hence the movement of the rigid body to which they are fixed), by using the inertia principle: the acceleration can be related to 
the reluctance to move (inertia) of a free mass contained in the sensor, when it is accelerated by an external force or torque (for accelerometer or gyroscope, respectively).

Accelerometer and gyroscope measure linear acceleration and angular velocity along and about a so-called sensible axis, respectively. Recent technology advances have led to the miniaturization of these sensors, which can be assembled and contained in small cases. An assembly of three orthogonal gyroscopes and three orthogonal accelerometers, mutually aligned to each other, is generally referred to as an Inertial Measurement Unit (IMU). An IMU measures three-dimensional (3D) linear acceleration and angular velocity with respect to the axes of a sensor-embedded system of reference, generally coinciding with the geometrical axes of the case in which the IMU is housed. Commercially available off-the-shelf inertial sensors turn up in small, light-weight, wireless units, that can be easily fixed to a body segment without affecting movement. Depending on their application, they are generally embedded with Bluetooth/wireless transmitters or SD cards, respectively for real time data streaming, or on-board long term data recording. In experimental settings, either the inertial sensors are fixed to a single body segment, or a network of two or more inertial sensors is used to retrieve synchronous data from multiple body segments. When using several inertial sensors, they need to be synchronized for maintaining data aligned in time, but commercial device based on more sensors already have an internal synchronization.

\subsection{Problems, artifacts and solutions}

Accelerometers and gyroscopes can be used to directly quantify the movement of a rigid body in terms of linear acceleration or angular velocity, to estimate other mechanical quantities (such as angular and linear displacement) and/or to extract other types of information from time- and frequency- domain signal analysis. Prior to listing all the information that can be retrieved from an inertial sensor for quantifying and characterizing human movement, it is important to introduce some typical problems and artifacts that affect the computation and that lead to the variables of interest, starting from the measured signal. This may help readers and users in critically discriminating robust inertial sensor based applications from those still suffering of poor reliability. Mechanical quantities typically affected by problems are all those estimated from numerical integration of the measured inertial sensor signals. These include: angular displacement (e.g., joint angles) obtained from numerical integration of angular velocity, and linear velocity and displacement (e.g., gait step length) as estimated, respectively, from first and second numerical integration of linear acceleration. Integration may be affected by a large time-increasing drift affecting the computed parameter, that makes the measure unreliable[9]. 
Another problem is that acceleration due to gravity has to be removed from the accelerometer data prior to numerical integration [10]. To this end, the orientation of the accelerometer in space has to be known. The orientation of a rigid body in space is typically computed by numerical integration of the angular velocities measured by a gyroscope. Drift affecting the angular displacement [11] can be reset each time an a priori known kinematic state of the system is detected. This can be done either using event identification, or by the accelerometer data, each time a (quasi-)static condition is detected. The practice of fusing gyroscope and accelerometer signals for the estimate of IMU orientation is typically referred to as "sensor fusion". Dedicated algorithms (usually already implemented in commercially available off-the-shelf IMUs) can correct the orientation computed from numerical integration of angular velocity solely with respect to gravity (the so called roll and pitch angles), but lack information on the sensor's orientation about the vertical direction (heading or yaw angle). The latter can be provided by using a magnetometer, which senses the local magnetic North, used as an absolute reference to reset drift about the vertical direction, so that a full 3D orientation of the sensor in space can be obtained[12,13]. Unfortunately, this approach suffers of interferences, due to the presence of ferromagnetic objects in the surrounding environment. Finally, the last concern to be aware of, when using inertial sensors in clinical human movement analysis, is the fixation of these sensors to the body segments. During this procedure, two aspects need attention: the sensor should be rigidly fixed to the body segment, to avoid motion artifacts, and the axes of the sensor's embedded reference system should be aligned with the anatomic axes of the segment the sensor is attached to. Many studies used accelerometers for detecting and removing motion artifacts affecting other kind of measures (for example electrocardiogram, electroencephalography, electromyography), whereas the motion artifacts affecting accelerometers is less investigated. The more rigid the connection between sensor and body segment, the more reliable the measure. However, spurious accelerations, such as artifacts due to soft tissue movement or external vibrations, can be minimized, through careful instrument placement, and signal filtering [14]. The other concern is the sensor alignment with the anatomic reference system, that can be performed either by manual alignment of the sensor on the body segment, or by ad hoc anatomic calibration procedure that will be further discussed. Of course, manual alignment may lack of accuracy, but it is easy to be performed and it can be corrected in post processing using gravity alignment. Besides, it is still acceptable in applications like gait stability and static balance assessment by trunk accelerometry or bidimensional joint angular kinematics, while it is not required for gait event identification.

\section{Clinical Applications of Wearable inertial devices}


In this review, we will report the most common areas of application of wearable inertial devices for human movement analysis: 1) gait analysis, further divided in 1a) upright gait stability (or dynamic balance assessment), 1b) spatio-temporal variables of gait and 1c) lower limb joint kinematics during gait; 2) stabilometry (or static balance assessment); 3) instrumented clinical tests; 4) upper body mobility assessment; 5) daily-life activity monitoring; 6) tremor assessment. As previously stated, each typology of use is analyzed both from a methodological, and from an applicative point of view.

\section{Gait analysis}

Conventional gait analysis has mainly focused on spatio-temporal gait parameters (such as walking speed, step length, step duration, stance-to-swing ratio), and on joint angular kinematics. In the 1990s, poor attention was given to trunk and head, since the mainstream idea was that the upper body was a static passenger unit of a locomotor apparatus, primarily located at lower limb level [1]. This idea was then challenged by empirical evidence. In fact, many following studies confirmed that the trunk plays a fundamental dynamic role during walking, by attenuating acceleration, ensuring the upright posture, and stabilizing the optical flow and vestibular signals[15-18]. Following these studies, interest in upper body movements during the gait has increased in the past decade. A review performed in 2008 analyzed 33 reports on the use of accelerometry for gait analysis, noting that the most common location for these devices was the trunk (36\% of studies), followed by head (21\%), and lower limbs (21\%)[8].

In the following, the applications of wearable inertial devices for assessing dynamic balance during gait, spatio-temporal gait parameters, and relevant joint kinematics are reviewed.

\subsection{Upright gait stability}

The expression "stable gait" may refers to three different features of physiological walking: 1) the ability of maintaining upright balance during walking [16], 2) step-to-step repeatable walking [19], or 3) a gait resilient to external and internal perturbations [20]. Ninety-two different quantitative measures of "gait stability", obtained using five different categories of devices, and mainly related to spatio-temporal gait parameters, lower limb joint kinematics, and upper body kinematics have been summarized in a wide review focused on gait stability [21].

Wearable devices have been used for all the above three types of stability, although the most common application was related to the dynamic balance of upper body during walking or "upright gait stability" [22]. The upper body plays a fundamental role for ensuring gait stability dynamically: 
its function of attenuating accelerations allows to stabilize the optical and vestibular informational flow. [15-17,23].

\subsubsection{Upright gait stability: Methodological approach}

The measure of acceleration dispersion is the most commonly used approach for assessing upper body stability using IMUs. To this end, acceleration root mean square (RMS) or more simply acceleration standard deviation (equivalent to the RMS, when the mean is removed from the signal), are usually evaluated along the 3 axes of sensors aligned to anteroposterior (AP), laterolateral (LL), and craniocaudal (CC) segmental axis. Since the 1990s, it has been suggested that acceleration RMS is a valid parameter for assessing balance during walking, differentiating between subjects with and without balance impairment or between walking on solid and soft terrains $(\mathrm{p}<0.05)$ [2426]. Subsequently, many other studies confirmed the validity of this approach in quantifying upright gait stability [27-29]. Further, high reliability of the three acceleration components, with sensor located at head, neck, trunk or shank level was found in test-retest conditions (a mean coefficient of multiple determination of 0.87 across all test conditions, ranging between 0.60 to 0.98 ) [30]. The most common sensor placement is on the lower trunk in correspondence of L2-L3 spinous process, as shown in Table 1. However, several studies have advocated normalizing upper body acceleration as a function of gait speed [26-28,31]. In fact, increasing or decreasing gait speed implies a corresponding quadratic rise or decline in acceleration amplitude. Therefore, acceleration parameters must be normalized between subjects and populations walking at different speeds, to assess only the dynamic instabilities, that are suitably imputable to balance impairment $[27,28]$. In summary, in the absence of a suitable normalization of accelerometric values, an increase in upper body accelerations can be attributed either to an unsteady speed due to gait instabilities, or to a rise in walking speed [27,32]. To take into account the relationship between acceleration and speed, many different methods have been suggested and validated [26-28,32,33].

Another important approach, for assessing upright gait stability, is the analysis of acceleration in the frequency domain. Among the many proposed parameters, a valid and reliable one is the harmonic ratio (HR). Gait harmony can be defined as the capacity to transfer the symmetry of our body into alternated, synchronized, symmetric and rhythmic movements, by means of intralimb [34], inter-limb[35] and lower-upper body [36,37] coordination. The HR, in particular, has focused on symmetry of movements, being defined as the ratio of the sum of even and odd (for antero-posterior axis, AP, and craniocaudal one, CC) or odd/even (for latero-lateral axis, LL) harmonic amplitudes, calculated via discrete Fourier transform, [16]. The trunk movement during a stride is theoretically formed by two symmetric units (the steps) along AP and CC, and by a single 
unit along LL. Thus, along AP and CC, all the even harmonics are in accordance with the theoretical symmetry of movement, whereas the odd harmonics can be considered as altering this harmony, and hence as noise. Therefore, higher values of HR correspond to a more physiologically temporally symmetric walking. Another parameters proposed for analysis in the frequency domain, and related to the smoothness of gait movements, is the relative power of the first signal harmonic, with respect to the total power of the signal [23].

\subsubsection{Upright gait stability: Clinical application}

According to the above reported definitions of "stable gait" [27,30,31], many different applications of IMUs have been used in clinical studies. The physiological importance of a stable gait is related to the stabilization of the body center of mass for avoiding falls and of the head for steadying the optic flow and increasing the control of equilibrium with a more effective processing of vestibular system signals[38, 39]. These and other advantages, such as keeping the hands free and seeing farther, might have spurred the development of upright walking in humans[39,40]. The ability of a subject to maintain balance during walking can be properly assessed by measuring upper-body kinematics[15,18] using optoelectronic systems [23,26,29] or wearable inertial devices as described above. Examples of trunk AP-acceleration collected by using an IMU (FreeSense, Sensorize, Roma, Italy, located with an elastic belt on the low back in correspondence of L2-L3 during the 10 meter walking test) have been shown in Figure 1.

In a review of 2011 [21], only 3 out of 92 outcome measures of kinematic measures used for assessing gait stability were performed using inertial sensors, but in the last 5 years, a large and growing body of literature has investigated the use of wearable inertial devices for assessing upright gait stability in healthy subjects [41], patients with stroke[27,32,42], children with cerebral palsy[28,43], people with low-back pain[44], those with cognitive impairments[45], subjects with autism and Down Syndrome[46], and people with lower limb amputation[47] (for a more recent specific review see[17]).

Since the nineties, dispersion of accelerations has been suggested as a valid parameter for assessing balance during walking, differentiating between subjects with and without balance impairment or between walking on solid and soft terrains[24,25]. Further, acceleration dispersion was found increasing with aging[48] and when subjects walk on an irregular surface[16], or in subjects with pathological conditions [27,28]. For example, Senden and colleagues enrolled 100 elderly subjects, finding that acceleration-RMS had a high discriminative power to classify elderly according to their clinical balance assessment performed by Tinetti scale [49]. 
About the analysis in frequency domain, the HR has been showed as a good predictor of the risk of falls in elderly, independently of their physical performance, in 1 year after the accelerometric assessment[50]. The HR of trunk acceleration was taken into account also in the study of Senden and colleagues, showing moderate association with the Tinetti score, but not entering into the final regression model for identifying subjects with unstable gait[49].

All these studies showed as the analysis of trunk accelerations can be informative about the excessive and disperse trunk movements strictly inter-connected with upright gait instabilities. The relationship between upright gait stability assessment performed with IMUs and risk of falls needs further studies, however it has recently been suggested that the involuntary control of locomotion can be favoured by the intrinsic gait temporal harmony, implying that its loss can increase the difficulties in controlling gait[51].

Researchers showed as also stride-by-stride acceleration variability, and not only its dispersion, is an important feature related to the risk of fall and/or to the clinical status of the patient. For example, the interstride trunk acceleration variability has been found as more sensitive to discriminate between fit and frail older adults than the step width variability [33]. Further, more irregular and variable trunk acceleration patterns and a reduced local stability were found when subjects are asked to walk performing a cognitive task (dual task) in the meantime [45].

\subsection{Spatio-temporal variables of gait}

Spatio-temporal variables of gait are generally referred to length and duration of step and stride, support and swing times, cadence (or step frequency) and walking speed. Spatio-temporal variables are probably the most commonly used data in clinical gait analysis for their straightforward clinical meaning. For example, walking speed has been used as a global index of locomotor deficits, prolonged stance phases and/or wide steps are associated with instabilities, short steps is a feature of pathological gait, as well as a reduced step frequency, whereas high step frequency often represents a compensatory strategy [1]. Spatio-temporal variables can be easily measured using stereophotogrammetric systems and force platforms, or instrumented insoles or sensorized mats. The advantages of using IMUs for detecting spatio-temporal gait parameters are related to the fact that they are easy-to-use, low-cost, non-obtrusive and wearable. The latter aspect allows for measuring spatio-temporal gait parameters in an environment without the conventional laboratory restrictions, such as under real-life conditions (see section 5) [52].

\subsubsection{Spatio-temporal variables of gait: Methodological approach}


The assessment of temporal parameters of gait using inertial sensors is based on gait events detection performed by means of signal feature extraction: peaks, valleys and zero-crossing are the typical features sought in the signal[53]. A variety of methods have been developed by adopting this approach. Generally, these features may be indicative of an impact in correspondence of a foot strike (mainly from accelerometer's signal either placed on the lower trunk or on the foot) or may reveal an inversion of rotation just like that of the shank at the end of stance phase which can be recognized from zero-crossing of sagittal angular velocity as measured by a gyroscope placed on the shank. However, when a method of feature extraction is proposed, it is generally "calibrated" using a gold standard (such as mats, cameras or force platforms) synchronized with the inertial sensor. Several approaches have been proposed for estimating spatio-temporal variables of gait using inertial sensors, some using solely accelerometers, some relying on gyroscope only and some using both in a sensor fusion approach. About sensor positioning, temporal event identification has been performed by placing the sensor on the lumbar spine[52-56], thigh [57], shank[58-60], foot[61] or on multiple segments of the lower limb[62,63]: generally, the closer the sensor is to the ground, the better gait event identification will be. Of course, lower trunk inertial sensing allows an easy setup since only one sensor is needed, but gait events identification may be tricky in pathological gait. A comparison of five different approaches for determining temporal parameters of gait by using a single inertial sensor on the lower trunk revealed, indeed, a high reliability of all the considered methods in a healthy population[64], while a similar study performed on pathological populations (elderly, post-stroke, Parkinson's disease and Huntington's disease) revealed that none of the tested methods outperformed the others in terms of accuracy of the gait parameters determination[65]. The error in identifying the stride duration, for example, resulted between the $4-5 \%$ of the actual values [65].

The only gait temporal parameter that maintains consistency in pathological gait using lower trunk inertial sensing is probably cadence, which does not require further signal elaborations, since it can be determined in the frequency domain rather than in time domain[33].

About the estimate of spatial parameters such as step length and velocity, many methodological approaches have been proposed and applied by researchers in clinical practice as well as implemented in commercially available solutions. One of these methods relies on estimating step length by double numerical integration of the AP-acceleration of the shank[60] or foot[61]. A second typology of approach is that of using an inverted pendulum model fed with the vertical excursion of the centre of mass, computing step length from double numerical integration of the CC-acceleration as measured using an accelerometer on the lumbar spine[54]. Another proposed possibility is based on a single IMU placed on the lower trunk estimating step length from a double 
integration of AP-acceleration[52]. A further methodological approach used a double inverted pendulum fed with the inclination on the sagittal plane of thigh and shank as estimated from numerical integration of angular velocity[58,66].

Another common type of analysis is the autocorrelation used for estimating the step frequency and the regularity of the signal (and hence parameters such as step and stride variability). A cyclic signal such as that of human gait produces autocorrelation coefficients with peak values for lags equivalent to the periodicity of the signal: plots and coefficient of an autocorrelation estimate can thus be used to inspect and quantify the cyclic structure of gait within a time series [67,68]. Unbiased autocorrelation procedures can be used to estimate cadence, step length and measures of gait regularity and symmetry in a valid and reliable manner [33].

Also the use of general linear regressive model has been proposed for an adaptive step length estimate algorithm operating with optimal parameters derived after measurement errors. This algorithm was applied to pedestrian navigation obtaining errors lower than $5 \%$ with respect to the actual walked distance [56].

With regard to the accuracy of such approaches, it has to be noted that numerical integration is always required. In the first and third approach, drift errors are compensated using kinematical reset using gait event detection by assuming foot velocity as zero and shank inclination as vertical during midstance, respectively[60,61]. In the lower trunk sensor approach, kinematical reset is not possible since the pelvis always moves during gait. Researchers tried to compensate for drift by using recursive direct and inverse numerical integration[57] (i.e., forcing signal to return to its initial condition at every integration step). Because of the higher signal-to-noise ratio and the lower variability of lower trunk vertical acceleration with respect to foot AP-acceleration, drift affecting vertical positional data is less challenging. This drift is usually removed applying a high-pass filter to the estimated positional data[52]. However, this drift correction approach can be hardly applicable in pathological gait where the amplitude of vertical lower trunk acceleration is lower and its variability is higher with respect to normal gait.

With regard to the ecological validity of such approaches for step length estimation, the second approach is less cumbersome (solely one sensor is needed) even if it is probably the less reliable as well, especially for spatial parameters of gait. The second approach requires two sensors (one on each foot), while the double inverted pendulum model is the most cumbersome (two sensors per side) but it also provides lower limb joint angular kinematic data.

\subsubsection{Spatio-temporal variables of gait: Clinical application}


Inertial sensing assessment of spatio-temporal variables of gait started to be applied in clinical contexts for functional electrical stimulation of peroneal muscle in patients with drop-foot: either shank or foot angular velocity and foot accelerations were used from the nineties for stance and swing detection for automating peroneal muscle stimulation during gait[69]. A comparison of all these approaches was performed in subjects with spinal-cord injury: the detection of initial and end contact was based on foot linear accelerations or foot sagittal angular velocity or shank sagittal angular velocity[70]. The results showed that all the three methods were accurate as foot switches for normal gait patterns $(\mathrm{p}>0.05)$, but shank angular velocity was significantly less accurate in patients $(\mathrm{p}<0.02)$. Lower body accelerometry approach was used for gait assessment in patients with diabetes (good reliability and validity of measures during single and dual walking tasks) [71] and for gait recovery assessment after total hip arthoplasty [72], both these studies used the same device to measure step length, step duration, cadence and gait speed. Double inverted pendulum approach was applied in Parkinson's disease[73] and in hip osteoarthritis and after total hip replacement[74] (see Table 1 for details on the performed measures and sensor location). A simple inverted pendulum model based on sagittal angular velocity and vertical acceleration measured by a single IMU placed on the shank was used for long-term monitoring of gait in subjects with Parkinson's disease[59]. Finally, temporal parameters of gait were identified from shank sagittal angular velocity for identifying gait patterns in subjects with anterior cruciate ligament reconstruction[75]. The information provided by these sensors (validated in the above studies) could be clinically useful both for a quantitative evaluation of patients' gait, for example for assessing the outcomes of rehabilitation or of another type of intervention [72,74,75], or for longterm monitoring $[59,73]$. When clinicians are interested in a quantitative assessment of spatiotemporal gait parameters they may use stereophotogrammetric systems (expensive in terms of costs and time), some simpler optoelectronic systems based on photocells or baropodometric platforms (but only on a pathway of few meters, limiting the measure of variation coefficients), or using wearable inertial devices. The latter approach has the advantages of reduced costs of devices and the possibility of monitoring patients on a long pathway without any laboratory restrictions. The last advantage of the absence of laboratory restriction is fundamental for allowing a long-term monitoring of daily life gait and other motor activities, that is possible only with wearable inertial devices. The latter issue will be further faced in the section about daily life activity monitoring. The disadvantages of these devices are related to the validity and reliability of these measures, that are generally good, but quite lower than those obtained using other systems estimating the spatiotemporal gait parameters in a more direct manner. 


\subsection{Joint kinematics during gait}

In laboratory settings, lower limb joint angular kinematics during gait is typically assessed by using camera-based stereophotogrammetric system which measures the 3D position of retro-reflective markers opportunely placed on anatomical landmarks. Once the position of these points is known, triaxial anatomical system of references can be defined and the relevant 3D joint angular kinematics can be computed by trigonometry. This approach is considered as the gold standard for its accuracy, although the analysis is limited to few steps. Furthermore, setup is cumbersome and instrumentation is expensive.

\subsubsection{Joint kinematics during gait: methodological approach}

First, let us distinguish between methodologies leading to the estimate of 2D joint angular kinematics (i.e., rotation on a single plane such as joint flexion-extension angle) and 3D joint angular kinematics (i.e., rotations on three planes such as joint flexion-extension, ab-adduction and internal-external rotation angles). The former is simpler from a computational point of view, while the latter requires more complex computation (sensor fusion), assumptions (joint constraints) and may require the use of magnetometers. Setup is not different between the two approaches, since the combination of accelerometer, gyroscopes and magnetometers does not increase the dimension of the sensor case with respect to a single-type sensor configuration.

With regard to the estimate of 2D joint angular kinematics, the first attempt goes back to 1990 when four biaxial accelerometers on the thigh and on the shank were employed for measuring accelerations on the segment's sagittal plane to solve rigid body equation of motion and computing knee flexion-extension angle[76]. The method did not require any numerical integration but, on the other hand, implied a cumbersome setup. This setup was lightened to one biaxial accelerometer per segment about fifteen years later by adding a single axis gyroscope to sensor configuration for directly measuring segments planar angular velocity instead of computing it from a pair of biaxial accelerometer as done before[77]. This approach was further enhanced recently when joint constraints were considered in computing joint kinematics (at knee level the root mean square error was $<3$ degrees and at ankle level $<1$ degree) [78]. A gyroscope-only approach was used for estimating knee flexion-extension by numerical integration of sagittal angular velocity of thigh and shank as measured by a single-axis gyroscope[79]. The same approach was used also compensating drift by using the inclination read from an accelerometer added to the gyroscope every time a static condition was detected, instead of using a reset every time thigh and shank are vertical in midstance[80]. This approach was further enhanced when resetting process was performed by a 
sensor fusion algorithm (with an average error ranging from 0.7 degrees during slow walking to 3.4 degrees during running) [81].

3D joint angular kinematics requires the estimate of 3D sensor's orientation in space. For this reason, these solutions are based on sensor fusion algorithms of IMU signals[82] and most of them imply the use of a magnetometer[83-85]. In some cases sensor orientation is readily furnished by proprietary "black-boxed" sensor fusion algorithms provided by the vendor of the sensor[83,84], while in other cases the sensor orientation algorithm is proposed by the researchers and explicated in the papers[82,85]. When dealing with 3D joint angular kinematics, the problem of a proper sensor to segment axes alignment raises up. This procedure, typically referred to as anatomical calibration of the sensor, can be performed using two approaches: a pure anatomical approach implies the use of anatomical markers for defining the axes of the anatomical system of reference[83], and a "functional" approach consisting of defining the axes of the segment as the direction of the rotation axis while performing selected joint rotations[82-85]. All of the mentioned methodological approaches for the estimate of 3D joint kinematics shower high reliability with respect to a video-based stereophotogrammetric system assumed as gold standard. However this reliability was higher for flexo-extension angles (variability ranging between 0.2 and 2.9 degrees) than for other angles such as internal-external rotation (variability ranging between 1.6 and 7.3 degrees) [83]. The strength of such approaches is the possibility to assess an unlimited number of gait strides during unconstrained walk, although users should be aware of ferromagnetic disturbances affecting magnetic sensors[86].

\subsubsection{Joint kinematics during gait: Clinical application}

It seems that the most of the scientific literature about the estimate of $3 \mathrm{D}$ joint angular kinematics by means of inertial sensors is methodological. Even when studies involved pathological populations, it was done more for validating the approach than to obtain new quantitative clinical insights about patients. To the best of authors' knowledge, the assessment of joint angular kinematics for gait analysis of subjects with anterior cruciate ligament injuries[87] and of children with cerebral palsy are the only cases in which inertial and magnetic sensors have been used for clinically assessing pathological gait[88]. For the authors of the present review, this might be symptomatic of a low feasibility of assessing 3D lower limb joint angular kinematics in pathological gait using inertial and magnetic sensors.

\section{Stabilometry (static balance assessment)}


Stabilometry is commonly used to quantify postural steadiness during quite standing on a force platform providing a global measure of posture control. Main parameters are typically extracted from the position of the application point of the resultant of ground reaction forces acting under the two feet, evolving on the horizontal plane as measured by the force platform, and coinciding with the centre of pressure in baropodometry. The parameters related to the centre of pressure sway during quite upright standing are sensitive to postural performance and allow for a straightforward and meaningful clinical interpretation of the results[89].

\subsection{Stabilometry: Methodological approach}

All the approaches for assessing standing balance by means of inertial sensors basically rely on the use of a single triaxial accelerometer placed on the lumbar spine, in correspondence of the centre of mass of the subject during quite standing. The main methodological approach using inertial sensors for static balance assessment relies on an inverted pendulum model to mimic body sway[90-93]. In (quasi-)static condition, the accelerometer measures solely gravity and its output is proportional to the alignment (or deviation) of the sensor's axis with respect to gravity. The time-varying position of the tip of the pendulum on the horizontal plane can be easily determined using trigonometry so that a sway path, such as other typical parameters of conventional stabilometry, can be obtained. Reliability and sensitivity of such approach has been successfully assessed against conventional stabilometry[90] under various sensory conditions [92] or pathology[93]. For example, test-retest reliability showed an intraclass correlation coefficient (ICC) ranging between 0.60 to 0.89 in healthy subjects and between 0.55 and 0.84 in patients with Parkinson's Disease [92]. Another, simple and reliable approach is that of quantifying body sway by assessing the root mean square (RMS) of the antero-posterior (AP) and latero-lateral (LL) accelerations[94]. As stated above, the RMS is a measure of dispersion of the signal and in static condition it can be, hence, considered as representative of the dynamic adjustments performed to control balance (the lowest the RMS the stablest the posture). The conditio sine qua non is that gravity, spread on the axes of the sensor according to the time-varying orientation in space of the sensor case, is subtracted from the accelerometer's readings so that RMS can be computed solely taking into account acceleration due to horizontal body sway. Finally, an alternative approach to time-domain signal analysis is that of using wavelet analysis (i.e., multi-level analysis of the frequency content of a signal) applied to the accelerometer readings[95]. This approach was proved to be even more sensitive than the inverted pendulum in distinguishing between healthy subjects and elderly subjects with frailty syndrome.

\subsection{Stabilometry: Clinical application}


Inertial sensing of human balance has been largely used in patients with Parkinson's Disease for detecting their postural abnormalities[96], assessing their postural strategies[97] and even for successfully training their static balance control with audio biofeedback[98]. Accelerometers have been used as well for detecting postural abnormalities in subjects with early-staged multiple sclerosis[99], in frail elderly population[95], subjects with a mild traumatic brain injury[100] and bilateral vestibular loss [101]. These researchers suggested an interesting application of IMUs not only for the postural assessment but also for the postural training of patients providing them biofeedback about their performances. However, stabilometric and baropodometric platforms can be easily used for the same objective, and being not largely more expensive than IMUs and often providing many more information. For these reasons, platforms seem to remain the best solution for clinical use. So, despite IMUs can also be used for stabilometric assessment obtaining reliable results, to purchase them for this purpose does not seem an optimal solution.

\section{Instrumented clinical tests}

Another clinically relevant application of inertial sensors is that for instrumenting clinical tests used for the assessment of motor function in simple mobility tasks. Gait tests such as the ten meter walking test[28,32] and the six minute walking[42] tests have often been used in daily clinical practice for their simple administration, and the only need of a chronometer and a pathway of a determined distance. The adjunction of IMUs during these tests can contribute providing more quantitative information, mainly those above reported about gait analysis, without any excessive complication of the tests. Other important instrumented tests not limited to walking are the sit-tostand (STS) and the more complex timed-up-and-go (TUG) test. The latter is usually composed by sit-to-stand, steady-state gait, turning and turn-to-sit.

\subsection{Instrumented clinical tests: methodological approach}

Generally, STS is typically equipped with a single sensor placed on the trunk of the subject, whereas TUG is extended to wrists, thigh and shank on both sides. Conventional metrics for assessing STS performance are time of sit-to-stand and stand-to-sit transitions as measured from event identification performed either on trunk sagittal angular velocity (by using a single gyroscope on the chest)[102] or on trunk sagittal angular displacement (using a single IMU on the lumbar spine) $[103,104]$. In the latter scenario, vertical acceleration can be additionally used to estimate external mechanical power for characterizing muscle work during raising from the chair [103]. Reliability of instrumented STS has been assessed against conventional movement analysis systems[103,104], whereas its sensitivity has been proved by comparing young and older adults 
$[105,106]$. For example, Regterschot and colleagues reported ICC $\geq 0.90$ and standard error of the measurement $\leq 9.9 \%$ [105]. Finally, in the instrumented TUG protocol, in addition to timing analysis, spatio-temporal variables of gait, knee flexion-extension, arm swing (in terms of angular displacement and velocity) and analysis of turning are provided as well[107].

\subsection{Instrumented clinical tests: clinical application}

Instrumented STS has been proposed and validated in patients with Parkinson's disease[108, 109], and used for assessing the functional status of elderly[110]. TUG protocol has been used for quantifying Freezing of Gait in Parkinson's disease[111] and performance under dual-task demands[112]. It is worthwhile to mention a series of papers showing combined methodological solutions based on networks of body-worn sensors, used to assess standing balance, gait analysis and TUG at the same time[113]. Such approach has been used in clinical settings as a diagnostic tool in subjects with Parkinson disease[114,115] and multiple sclerosis[116], and as a general monitoring tool for balance and gait rehabilitation[117]. Figure 2 shows the raw data obtained with an IMU during the execution of TUG test by a patient with stroke.

\section{Upper body mobility assessment}

Upper Iimb and spine kinematics (assessing range of motion or quantifying back loading, respectively) is typically assessed in laboratory settings using stereophotogrammetric systems [118]. In this section, methods and applications for upper body kinematic analysis during motor tasks different from gait (already reported in section 1.3) are described.

\subsection{Upper body mobility assessment: methodological approach and clinical application}

While the methodological bases for the estimate of spine and upper limb joint angular kinematics by means of inertial and magnetic sensors are well discussed in the scientific literature, clinical application of such approaches is still little explored. With regards to upper limb joint kinematics, most of papers are, indeed, methodological and focused to show how to estimate 3D shoulder and elbow angular kinematics by means of inertial[119,120] or inertial and magnetic[121-123] sensors, facing as well the requirement of the sensor-to-segment axes alignment[122,124]. Those approaches usually require to know the $3 \mathrm{D}$ orientation in space of thorax, upper arm and forearm. The use of chain-linked models based on joint constraints[119,120] allows to avoid the use of magnetometer that, as discussed in the previous sections, is used to extend the estimate of the orientation of the IMU to a 3D space. All these methodological approaches have been validated against a gold standard (stereophotogrammetry or robot arms). One of the most relevant and clinically-significant 
methodological approach is that of estimating scapular and upper arm orientation for the quantitative assessment of the scapular rhythm (intra- and inter-operator agreement was acceptable: median coefficient of multiple correlation $\geq 0.85$ )[125]. The solely clinical application of wearable sensors for upper limb kinematics is that assessing scapular dyskinesis in baseball pitchers[126].

Easier approaches for the assessment of shoulder mobility during arm elevation have also been proposed. Setup is less cumbersome since a single IMU is used and placed on the upper arm, but the level of detail is limited to planar shoulder mechanics[127]. Reliability of such approach has been assessed on a healthy population (ICC $\geq 0.93$, coefficient of multiple determination $>0.84$, mean error $<1$ degree)[128], while its practical usability in a clinical context was proved by monitoring shoulder ROM recovery after slap surgery throughout the rehabilitation program. The main limitation of an approach based on the use of a single sensor is related to the fact that the analysis of the movement of a single body segment could be affected by compensation strategies acting on the proximal adjacent body segment, for example when shoulder range of motion is measured by an IMU placed on the arm, a concurrent trunk tilt can generate a bias on the accelerometric signal.

\section{Daily life activity assessement}

One of the most important advantages of wearable inertial sensors is to allow for moving conventional human movement analysis from laboratory out to ambulatory settings with a reasonable reliability. Furthermore this technology also opened up a brand new perspective: longterm and unconstrained monitoring of human movement in real-life conditions. Monitoring the amount of daily life activity is important in older adults since physical activity is associated with both physical and mental health and is a primary determinant of quality of life, in children and obese subjects for understanding their lifestyle and quantify the prevalence of sedentarism, in pathological subjects (both with neurological and orthopedic disorders) to have an understanding of their autonomy, especially after rehabilitation or surgery. Many methods are reported in literature and the information provided is extremely wide ranging, deserving a more specific and extensive review (such as [129]). Here, we briefly summarized this literature to provide an overlook of this field of application of wearable inertial devices and of the two main reported approaches. In fact, IMUs can be used as actigraphs for quantifying the volume of activity or for identifying the type of performed activities. Estimating the time of sedentary behaviours (lying or sitting), time of activity, and detecting number of dynamic events independently by the type of actions are examples of the former, while acceleration analysis for categorizing movements in sitting or lying or stepping, or for estimating the energy expenditure are examples of the latter [130]. 


\subsection{Daily life activity assessment: methodological approach}

The methodological approach that turns an inertial sensor into an activity monitor is quite straightforward and classifiable in few steps: 1) accelerometers are basically used to distinguish between a moving or still subject; 2) accelerometers are used for sensing segments' inclination in order to provide information on the types of subject's posture or movements.

One uniaxial accelerometer placed on the trunk and one uniaxial accelerometer placed on the thigh (both with their sensible axis aligned along the cranio-caudal direction) have been showed to be sufficient for distinguishing among different postures, such as sitting, standing or lying, or motor activities [14,130]. However, the quantification (classification) of the amount of movement (low, moderate, high) is not so easy. The key point is the correct identification of activity thresholds. For this reason, a number of population-specific threshold have been proposed and validated in a variety of populations such as toddlers[131], children[132], sedentary children[132], youth[129], adults[134], subjects with multiple sclerosis[135] and Parkinson's disease[136-138]. Accuracy in activity identification resulted ranging between $81.7 \%$ and $99.9 \%$ depending on the type of performed activity [137]. Typical outcome of such assessment is a pie chart, generally representing a 24 hours period of time, with slices representing percentage of static and dynamics activities.

\subsection{Daily life activity assessment: clinical application}

Scientific literature on clinical applications of inertial sensors based daily life activity monitors in the last two decades is wide and nearly hardly revisable in a systematic manner [139]. As a reference for readers, inertial sensors have been employed for daily life activity monitoring in Parkinson's disease[140], stroke[141], hip arthoplasty[142], chronic diseases[143], elderly[144] and obese[145] populations. The most significant and promising solution is probably that of fall detection and quantification of the risk of fall[146]. In this field, two alternative applications deserved a mention: the use of four accelerometers (one for each limb) for assessing mobility in newborns to assess the risk of cerebral palsy (for example measuring less movements from one side)[147] and the use of five IMUs for assessing the quantity of movements in different motor rehabilitation programs in children with cerebral palsy[148].

\section{Tremor assessment}

From a physiological point of view, tremor can be defined as any involuntary approximately rhythmic and roughly sinusoidal movement that can be detected in an oscillating limb[149,150]. Tremor is hence a change of positions, but rhythmic and sinusoidal features are preserved when the 
acceleration is analysed. In fact, the second derivative of a sinusoidal function is still a sinusoidal function with the same frequency of oscillation of the original function. Other advantages of using an accelerometer (besided those already reported of low weight and low cost) are that acceleration is proportional to the total force acting on the limb for the second law of dynamics and that acceleration may reveals in a more clear manner the high-frequency components, because faster oscillations will generate more power within higher frequencies[151].

\subsection{Tremor assessment: methodological approach}

An accelerometer attached to a limb segment can be easily used to assess the frequency and amplitude of tremor, both widely varying with respect to the type and degree of pathology [152,153]. An accelerometer has the advantage of being usually slight and wireless, but it could be not enough slight for example for assessing a finger's tremor. It is known that the application of an external load on the treming body part, may reduce both amplitude and frequency of rest tremor and altering these features in postural or action tremor (rest tremor is that occurring when the body part is fully supported against gravity, postural tremor is that in which limb is voluntary mantained firm against gravity, action tremor is that occurring during any type of voluntary movement[152]). In this cases optoelectronic[151], or electromagnetic[154] systems can be used. Another possible problem in the accelerometric assessment of tremor is the gravitational artifact that is larger at lower frequencies. A proposed solution was to use two accelerometers mounted in parallel[155].

For a more complete assessment of tremor, accelerometry has often been coupled to electomiography to highlight which agonist and antagonist muscles may be at the basis of tremor[156].

\subsection{Tremor assessment: clinical application}

The identification of the main frequency of oscillation may even help clinicians in formulating a diagnosis. In fact, the main frequency of essential tremor, as well as tremor caused by alcohol or drug withdrawal, or metabolic disturbances ranges from 5 to $9 \mathrm{~Hz}$, and it is different from the main frequency of tremor in Parkinson's disease, multiple system atrophy, progressive supranuclear palsy ranging from 3 to $6 \mathrm{~Hz}$. Other tremors, such as psychogenic one, that due to drug assumption, or due to cerebellar lesions have a wider range for the main frequency going from 3 to $10 \mathrm{~Hz}[152]$.

Physiological tremor is a normal variant, occurring at frequency of 8 to $12 \mathrm{~Hz}$ in the hands yet as slow as $6.5 \mathrm{~Hz}$ in the other parts of the body during posture. Obviously its amplitude is very low[157]. Figure 3 shows the data of dorso-ventral hand accelerations collected (using Vibracting, 
Sensorize, Rome, Italy) in a healthy subject and in a subject with Parkinson's Disease with and without a weight of $1 \mathrm{~kg}$ located around the wrist.

\section{Expert commentary}

Recent advances in miniature devices, as well as mobile and ubiquitous computing, have fostered a dramatic growth of interest for wearable technology based on inertial sensors. Despite this review was not a systematic one, also because too many papers exist on the use of IMUs in the many fields of human movement analysis, it provides an overview, based on authors' experience and on the many cited studies, for technicians and clinicians about the advantages and disadvantages related to the use of these sensors. Less expensive and more easy to use than other systems used in human movement analysis, wearable sensors have evolved to the point that they can be considered ready for being part of routine clinical evaluations. This is due not only to the tremendous increase in research efforts devoted to wearable sensors in the past few years but also to the large number of commercial companies that have recently started investing in the development of wearable products for clinical applications[158].

In particular, we have identified seven main fields related to human movement analysis in which IMUs have been applied. These fields are related to the assessment of: upright gait stability, spatiotemporal gait parameters, joint kinematics during walking, posture, upper body mobility, tremor, and to the monitoring of daily life activities. For all these fields, most of the cited studies reported positive results in terms of validity and reliability of using IMUs. However, the clinical diffusions of IMUs among these seven fields is different. Scientific literature usually suffers of the potential bias due to the difficulties in publishing negative results with respect to positive ones [159], and it may contribute to enlarge the discrepancy between research results and clinical applications. Therefore, out of the seven identified fields of application, the potential of IMUs as real added value for human movement analysis will be reconsidered at the light of three aspects: the amount of publications reporting positive results, the level of accuracy and reliability of the measures, and, finally, the level of computational complexity behind the determination of the parameters of interest (i.e., information extracted from derived mechanical quantities are more prone to errors with respect to those directly extracted from the measured signal).

At the light of these criteria, the assessments of upright gait stability and of daily life activities seem to be the most important fields in which IMUs represent the most suitable technological solution and hence the gold standard. In fact, only the development of IMUs favoured researches and clinical applications in these two fields [30,137]. Other two important fields of application are the instrumentation of clinical tests and the assessment of upper body mobility. The importance of 
IMUs in these two last fields are mainly related to the fact that, at the moment, clinicians still perform these assessments mainly with too simple tools such as chronometers and goniometers. Analogously, tremor is often assessed using clinical criteria, whereas IMUs can provide a more objective information related to the frequency and intensity of oscillations, especially in absence of a well defined gold standard. About spatio-temporal gait parameters, IMUs have achieved a good level of accuracy for healthy subjects, but seem to be still far from gold standard in pathologicalgait - Analogous observation can be made for joint kinematics, where IMUs seem to be a valid alternative to conventional gait analysis certainly for the assessment of sagittal joint kinematics (i.e flexo-extensions), both in healthy and pathological gait, while its reliability seems to decrease on the coronal and transverse planes in correspondence of higher signal-to-noise ratios [83]. Finally, IMUs proved reliability in assessing the static postural control of both healthy and pathological subjects [92] but, because of the affordability and ease of use of conventional stabilometric platforms, the advantage of using IMUs is not straightforward.

\section{Five year perspective view}

We expect that the interest for wearable inertial systems will even increase in the next years, becoming a common tool for clinicians involved in the motor assessment and rehabilitation. It implies that the wearable IMUs will be widely commercialized not only for research applications but also as clinical tools.

Likely, we already have in our pocket the most important next application of these sensors: smartphones already contain inertial devices, and they will be the perfect candidate for a continuous physical monitoring of subjects activities. They also include internet connection to send data to a medical doctor or to some clinical databases, and also GPS-systems for the assessment of displacement (including elevation) during outdoor activities. The smartphones are widely popular devices, and the rapidity of app development is a fertile soil for developing many low-cost systems providing a lot of data about daily life activities of subjects (for example, many apps assessing running performance are already available for joggers). Recent studies showed a degree of accuracy using smartphone with a gait analysis app comparable to that of a conventional tri-axial accelerometer specifically developed for gait assessment (ICC ranging between 0.75 to 0.90 , validity $\mathrm{p}<0.01$ ) $[160,161]$.

Further, with the development of motion-sensing technology, an increasing number of wearable sensors will be developed for gait analysis in the future, increasing the use of wearable sensors in the clinical field. Bonato[162] supported the idea of this prevision of a further increment also for the potential use of wearable inertial devices in daily life monitoring patients over extensive periods of 
time, similarly to the ambulatory systems for electrocardiographic monitoring (such as the Holter) which has been part of the routine evaluation of cardiovascular patients for almost three decades. Another potential application of these devices will be their combined use with other machines. In fact, we think that in the next years, these devices will be more and more used in clinical practice, not only for research purposes and not only for the assessment of motor functioning, but they will also be included in other devices specifically developed for a clinical intervention such as for rehabilitation. For example, some authors[163] suggested to use electromiographyc biofeedback for a behavioural relaxation training in patients with essential tremor. With the same purpose, it is possible to use accelerometers coupled with a proper software for providing a biofeedback about tremor. Another example is a balance training in patients with poor equilibrium performed using IMUs[98]. Many companies are already using IMUs integrated in video-game based rehabilitation systems such as in the Riablo ${ }^{\mathrm{TM}}$ system (CoRehab, Trento, Italy) [164], as shown in Figure 4, in the Werium system (Madrid, Spain) [165,166], or in other systems such as that Microgate (Bolzano, Italy) is developing in a manner similar to Mirelman and colleagues[98].

So, it is conceivably that in the next few years, wearable inertial devices will allow human movement analysis to do a step further, from the assessment to a combined approach including assessment and rehabilitation at the same time.

\section{Alternative devices}

As stated above, the gold standard for a laboratory of human movement kinematic analysis is composed of a multi-camera motion capture system with passive or active markers [4-7]. However, this standard gait analysis requires specialized laboratories, expensive equipment, and lengthy setup and post-processing times, with limitations in terms of the moving area and gait cycles. Despite these problems this system remains the best instrument in terms of valid and reliable measures, making it the reknown gold standard for the human movement analysis. Other devices exist for measuring specific aspects of human movements, such as electrogonyometers for joint angle, or sensorized mats (including baropodometric platforms) and optoelectronic systems with photocells for spatiotemporal parameters of walking. However these alternative devices do not have the benefit during the assessment of movements to enable the subject to walk relatively unrestricted, even out of laboratory, measuring their performance (it means also in real life condition) and not only their capability (i.e. their ability measured in the standard environment of a laboratory) [167]. 


\section{Key points}

1. From the beginning of the new millennium, technology advances in the field of motion measurement techniques allowed to measure kinematics of body segments without the need of camera-based systems using wearable inertial sensors.

2. Some of the potential benefits of using wearable inertial devices to assess movements in clinical settings include the low cost, small dimensions and light weight of these devices, and the absence of any limitation of the testing environment to a laboratory.

3. The main problems of IMUs are: drift affecting numerical integration in estimation a nondirectly measured parameters, artefacts due to gravity acceleration, needs of a correct alignment between sensor and anatomical axes. Many algorithms have been proposed to compensate these problems.

4. The most common and promising areas of application of IMUs are gait analysis, instrumented clinical tests; daily-life activities, and tremor.

5. Gait analysis performed by using IMUs may allow for suitably assessing upright gait stability, and spatio-temporal variables of gait;

6. One of the most important advantages of wearable IMU is the possibility of collecting data without laboratory restrictions: it allows for a continuous and objective assessment of activities of daily living.

7. IMUs also allow the possibility of a quantitative assessment of tremor in terms of amplitude and frequency.

8. The interest for wearable inertial systems will probably even increase in the next years, becoming a common tool for clinical motor assessment.

9. In the next future, these devices will also be combined with other machines, for example embedded in video-game based therapy and in neurorobots for rehabilitation.

\section{Declaration of Interest}

This review has been financed by the Line of Research "Cognitive and Motor Neurorehabilitation in adults and developmental age" of Santa Lucia Foundation. The authors have no other relevant affiliations or financial involvement with any organization or entity with a financial interest in or financial conflict with the subject matter or materials discussed in the manuscript apart from those disclosed. 


\section{References}

Papers of special note have been annotated as:

* Of interest

** Of considerable interest

1. Perry J. Gait Analysis: Normal and Pathological Function. Slack Incorporated, USA, 1992.

2. Cappozzo A, Della Croce U, Leardini A, Chiari L. Human movement analysis using stereophotogrammetry. Part 1: theoretical background. Gait Posture. 2005;21:186-96.

3. Kirtley C. Clinical gait analysis: theory and practice. Churchill Livingstone, Oxford, UK, 2006.

4. Gavrila D.M., Davis L.S. 3-D Model-based tracking of humans in action: A multi-view approach. Proceedings of the IEEE Computer Vision and Pattern Recognition; San Francisco, CA, USA, 1996.

5. Cappozzo A., Della Croce U., Leardini A., Chiari L. Human movement analysis using stereophotogrammetry. Part 1: Theoretical background. Gait Posture 2005;21:186-196.

6. Chiari L., Della Croce U., Leardini A., Cappozzo A.Human movement analysis using stereophotogrammetry. Part 2: Instrumental errors. Gait Posture 2005;21:197-211.

7. Kim C.M., Eng J.J. Magnitude and pattern of 3D kinematic and kinetic gait profiles in persons with stroke: Relationship to walking speed. Gait Posture 2004;20:140-146.

8. Kavanagh JJ, Menz HB. Accelerometry: a technique for quantifying movement patterns during walking. Gait Posture 2008;28(1):1-15.

9. Woodman OJ. An introduction to inertial navigation. Technical Report UCAM-CLTR-696: University of Cambridge, 2007.

10. Veltink PH, Slycke P, Hemssems J, et al. Three dimensional inertial sensing of foot movements for automatic tuning of a two-channel implantable drop-foot stimulator. Med Eng Phys 2003;25(1):21-8.

11. Pasciuto I, Ligorio G, Bergamini E, et al. How Angular Velocity Features and Different Gyroscope Noise Types Interact and Determine Orientation Estimation Accuracy. Sensors (Basel) 2015; 15(9):23983-4001.

12. Sabatini AM Estimating three-dimensional orientation of human body parts by inertial/magnetic sensing. Sensors (Basel) 2011; 11(2):1489-525.

13. Bergamini E, Ligorio G, Summa A, et al. Estimating orientation using magnetic and inertial sensors and different sensor fusion approaches: accuracy assessment in manual and locomotion tasks. Sensors (Basel) 2014; 14(10):18625-49.

14. Mathie MJ, Coster AC, Lovell NH, et al. Accelerometry: providing an integrated, practical method for long-term, ambulatory monitoring of human movement. Physiol Meas 2004; 25(2):R1-20.

15. Winter DA. Human balance and posture control during standing and walking. Gait Posture 1995;3(4):193-214.

16. Menz HB, Lord SR, Fitzpatrick RC. Acceleration patterns of the head and pelvis when walking on level and irregular surfaces. Gait Posture, 2003;18:35-46. * of interest 
This paper was one of the first studies focused on upper body during walking, after those of Cappozzo already performed in eighties. The results suggested the importance of measuring accelerations for assessing postural control system at pelvis and head levels during walking, and that subjects adapt their stepping pattern on irregular surfaces to ensure that the head remains stable.

17. Iosa M, Fusco A, Morone G, Paolucci S. Development and decline of upright gait stability. Front Aging Neurosci. 2014;6:14. ** of high interest

This wide review analysed from a neuroscientific point of view, the importance of upright gait stability, how it is developed in children, and how it is reduced with aging, under pathological conditions, and even under particular environmental or testing conditions.

18. Kavanagh JJ, Barrett RS, Morrison S. Upper body accelerations during walking in healthy young and elderly men. Gait Posture 2004;20(3):291-98.

19. Dingwell JB, Marin, LC. Kinematic variability and local dynamic stability of upper body motions when walking at different speeds. J. Biomech. 2006; 39(3): 444-452.

20. Terrier P, Dériaz O. Kinematic variability, fractal dynamics and local dynamic stability of treadmill walking. J. Neuroeng. Rehabil. 2011; 8,12.

21. Hamacher D, Singh NB, Van Dieën JH, Heller MO, Taylor WR. Kinematic measures for assessing gait stability in elderly individuals: a systematic review. J. R. Soc. Interface. 2011: 8,16821698.

22. Cappozzo A. Analysis of the linear displacement of the head and trunk during walking at different speeds. J Biomech. 1981,14:411-25. ** of high interest

This was one of the first studies analyzing head and trunk during walking. Still in nineties the upper part of body was simply considered as a passenger during walking. This study of early eighties was instead focused on upper body resulting a precursor of the many studies more recently performed.

23. Mazzà C, Iosa M, Pecoraro F, Cappozzo A. Control of the upper body accelerations in young and elderly women during level walking. J Neuroeng Rehabil. 2008;5:30.

24. Moe-Nilssen R. A new method for evaluating motor control in gait under real-life environmental conditions. Part 1: The instrument. Clin Biomech (Bristol, Avon). 1998;13(4-5):320-327.

25. Moe-Nilssen R. A new method for evaluating motor control in gait under real-life environmental conditions. Part 2: Gait analysis. Clin Biomech (Bristol, Avon). 1998;13(4-5):328-335.

26. Marigold DS, Patla AE. Age-related changes in gait for multi-surface terrain. Gait Posture 2008;27(4):689-96.

27. Mizuike C, Ohgi S, Morita S. Analysis of stroke patient walking dynamics using a tri-axial accelerometer. Gait Posture 2009;30(1):60-64.

28. Iosa M, Marro T, Paolucci S, Morelli D. Stability and harmony of gait in children with cerebral palsy. Res Dev Disabil 2012;33(1):129-35. 
29. Lamoth CJ, Meijer OG, Wuisman PI, van Dieën JH, Levin MF, Beek PJ. Pelvis-thorax coordination in the transverse plane during walking in persons with nonspecific low back pain. Spine 2002;27(4):E92-99.

30. Kavanagh JJ, Morrison S, James DA, Barrett R. Reliability of segmental accelerations measured using a new wireless gait analysis system. J Biomech. 2006;39(15):2863-72.

31. Kavanagh JJ. Lower trunk motion and speed-dependence during walking. J Neuroeng Rehabil. 2009;6:9.

32. Iosa M, Fusco A, Morone G, Pratesi L, Coiro P, Venturiero V, De Angelis D, Bragoni M, Paolucci S. Assessment of upper-body dynamic stability during walking in patients with subacute stroke. J Rehabil Res Dev. 2012;49(3):439-50.

33. Moe-Nilssen R, Helbostad JL. Estimation of gait cycle characteristics by trunk accelerometry. J Biomech. 2004;37(1):121-6.

34. Borghese NA, Bianchi L, Lacquaniti F. Kinematic determinants of human locomotion. J Physiol. 1996;494:863-79.

35. Reisman DS, Block HJ, Bastian AJ. Interlimb coordination during locomotion: what can be adapted and stored? J Neurophysiol. 2005;94(4):2403-15.

36. Cappozzo A. Low frequency self-generated vibration during ambulation in normal men. J. Biomech. 1982;15: 599-609.

37. Iosa M, Mazzà C, Pecoraro F, Aprile I, Ricci E, Cappozzo A. Control of the upper body movements during level walking in patients with facioscapulohumeral dystrophy. Gait Posture. 2010;31(1):68-72.

38. Berthoz A, Pozzo T. Head and body coordination during locomotion and complex movements. In: Swinnen S, Heuer H, Massion J, Casaer P, editors. Interlimb coordination. San Diego: Academic Press, 1994.

39. Spoor F, Wood B, Zonneveld F. Implications of early hominid labyrinthine morphology for evolution of human bipedal locomotion. Nature 1994; 369(6482), 645-648.

40. Reed ES. Encountering the world: Toward an ecological psychology. New York: Oxford University Press, 1996.

41. Josa M, Fusco A, Morone G, Paolucci S. Effects of visual deprivation on gait dynamic stability. ScientificWorldJournal. 2012;2012:974560.

42. Iosa M, Morone G, Fusco A, Pratesi L, Bragoni M, Coiro P, Multari M, Venturiero V, De Angelis D, Paolucci S. Effects of walking endurance reduction on gait stability in patients with stroke. Stroke Res Treat. 2012;2012:810415.

43. Iosa M, Morelli D, Marro T, Paolucci S, Fusco A. Ability and stability of running and walking in children with cerebral palsy. Neuropediatrics. 2013;44(3):147-54. 
44. Henchoz Y, Soldini N, Peyrot N, Malatesta D. Energetics and mechanics of walking in patients with chronic low back pain and healthy matched controls. Eur J Appl Physiol. 2015;115(11):2433-43.

45. Lamoth CJ, van Deudekom FJ, van Campen JP, Appels BA, de Vries OJ, Pijnappels M. Gait stability and variability measures show effects of impaired cognition and dual tasking in frail people. J Neuroeng Rehabil. 2011;8:2.

46. Iosa M, Morelli D, Nisi E, Sorbara C, Negrini S, Gentili P, Paolucci S, Fusco A. Assessment of upper body accelerations in young adults with intellectual disabilities while walking, running, and dualtask running. Hum Mov Sci. 2014;34:187-95.

47. Iosa M, Paradisi F, Brunelli S, Delussu AS, Pellegrini R, Zenardi D, Paolucci S, Traballesi M. Assessment of gait stability, harmony, and symmetry in subjects with lower-limb amputation evaluated by trunk accelerations. J Rehabil Res Dev. 2014;51(4):623-34.

48. Menz HB, Lord SR, Fitzpatrick RC. Age-related differences in walking stability. Age Ageing. 2003;32(2):137-42.

49. Senden R, Savelberg HH, Grimm B, Heyligers IC, Meijer K. Accelerometry-based gait analysis, an additional objective approach to screen subjects at risk for falling. Gait Posture 2012;36(2): 296-300.

50. Doi T, Hirata S, Ono R, Tsutsumimoto K, Misu S, Ando $H$. The harmonic ratio of trunk acceleration predicts falling among older people: results of a 1 -year prospective study. J Neuroeng Rehabil. 2013;10:7.

51. Iosa M, Fusco A, Marchetti F, Morone G, Caltagirone C, Paolucci S, Peppe A. The golden ratio of gait harmony: repetitive proportions of repetitive gait phases. Biomed Res Int. 2013;2013:918642.

52. Zijlstra W, Hof AL. Assessment of spatio-temporal gait parameters from trunk accelerations during human walking. Gait Posture 2003;18(2):1-10.

53. Rueterbories J, Spaich EG, Larsen B, et al. Methods for gait event detection and analysis in ambulatory systems. Med Eng Phys 2010; 32(6):545-52.

54. McCamley J, Donati M, Grimpampi E, et al. An enhanced estimate of initial contact and final contact instants of time using lower trunk inertial sensor data. Gait Posture 2012;36:2-4.

55. Gonzalez RC, Lopez AM, Rodriguez-Uria J, et al. Real-time gait event detection for normal subjects from lower trunk accelerations. Gait Posture 2010;31:322-5.

56. Shin SH, Park CG. Adaptive step length estimation algorithm using optimal parameters and movement status awareness. Med Eng Phys 2011;33:1064-71.

57. Kose A, Cereatti A, Della Croce U. Bilateral step length estimation using a single inertial measurement unit attached to the pelvis. J Neuroeng Rehabil 2012;9:9.

58. Aminian K, Najafi B, Büla C, et al. Spatio-temporal parameters of gait measured by an ambulatory system using miniature gyroscopes. J Biomech. 2002 May;35(5):689-99.

59. Moore ST, MacDougall HG, Gracies JM, et al. Long-term monitoring of gait in Parkinson's disease. Gait Posture 2007; 26(2):200-7. 
60. Trojaniello D, Cereatti A, Pelosin E, et al. Estimation of step-by-step spatio-temporal parameters of normal and impaired gait using shank-mounted magneto-inertial sensors: application to elderly, hemiparetic, parkinsonian and choreic gait. J Neuroeng Rehabil 2014; 11:152. * of interest

This study was the first one performing a robust method for computing spatio-temportal parameters from IMUs tested in some different pathologies.

61. Sabatini AM, Martelloni C, Scapellato S, et al. Assessment of walking features from foot inertial sensing. IEEE Trans Biomed Eng 2005; 52(3):486-94.

62. Lau H, Tong K. The reliability of using accelerometer and gyroscope for gait event identification on persons with dropped foot. Gait Posture 2008; 27(2):248-57.

63. Hanlon M, Anderson R. Real-time gait event detection using wearable sensors. Gait Posture 2009;30(4):523-7.

64. Trojaniello D, Cereatti A, Della Croce U. Accuracy, sensitivity and robustness of five different methods for the estimation of gait temporal parameters using a single inertial sensor mounted on the lower trunk. Gait Posture 2014; 40(4):487-92.

65. Trojaniello D, Ravaschio A, Hausdorff JM, et al. Comparative assessment of different methods for the estimation of gait temporal parameters using a single inertial sensor: application to elderly, poststroke, Parkinson's disease and Huntington's disease subjects. Gait Posture 2015; 42(3):310-6.

66. Li Q, Young M, Naing V, et al. Walking speed estimation using a shank-mounted inertial measurement unit. J Biomech 2010; 43(8):1640-3.

67. Moe-Nilssen R, Helbostad JL Interstride trunk acceleration variability but not step width variability can differentiate between fit and frail older adults. Gait Posture. 2005;21(2):164-70.

68. Nelson-Wong E1, Howarth S, Winter DA, Callaghan JP. Application of autocorrelation and cross-correlation analyses in human movement and rehabilitation research. J Orthop Sports Phys Ther. 2009;39(4):287-95.

69. Willemsen AT, Bloemhof F, Boom HB. Automatic stance-swing phase detection from accelerometer data for peroneal nerve stimulation. IEEE Trans Biomed Eng 1990; 37(12):1201-8.

70. Jasiewicz JM, Allum JH, Middleton JW, et al. Gait event detection using linear accelerometers or angular velocity transducers in able-bodied and spinal-cord injured individuals. Gait Posture 2006; 24(4):502-9.

71. de Bruin ED, Hubli M, Hofer P, et al. Validity and reliability of accelerometer-based gait assessment in patients with diabetes on challenging surfaces. J Aging Res 2012;2012:954378.

72. van den Akker-Scheek I, Stevens M, Bulstra SK, et al. Recovery of gait after short-stay total hip arthroplasty. Arch Phys Med Rehabil 2007; 88(3):361-7.

73. Salarian A, Russmann H, Vingerhoets FJ, et al. Gait assessment in Parkinson's disease: toward an ambulatory system for long-term monitoring. IEEE Trans Biomed Eng 2004; 51(8):1434-43. 
74. Aminian K, Trevisan C, Najafi B, et al. Evaluation of an ambulatory system for gait analysis in hip osteoarthritis and after total hip replacement. Gait Posture 2004; 20(1):102-7.

75. Patterson MR, Delahunt E, Sweeney KT, et al. An ambulatory method of identifying anterior cruciate ligament reconstructed gait patterns. Sensors (Basel) 2014; 14(1):887-99.

76. Willemsen AT, van Alste JA, Boom HB. Real-time gait assessment utilizing a new way of accelerometry. J Biomech 1990; 23: 859-63.

77. Dejnabadi H, Jolles BM, Aminian K. A new approach to accurate measurement of uniaxial joint angles based on a combination of accelerometers and gyroscopes, IEEE Trans Biomed Eng 2005; 52(8):1478-1484.

78. Seel T, Raisch J, Schauer T. IMU-based joint angle measurement for gait analysis. Sensors (Basel) 2014; 14(4):6891-909.

79. Tong K, Granat M. A practical gait analysis system using gyroscopes. Med Eng \& Phys 1999; 21(2):87-94.

80. Mayagoitia RE, Nene AV, Veltink PH. Accelerometer and rate gyroscope measurement of kinematics: an inexpensive alternative to optical motion analysis systems. J Biomech 2002; 35(4):53742.

81. Cooper G, Sheret I, McMillan L, et al. Inertial sensor-based knee flexion/extension angle estimation. J Biomech 2009; 42(16):2678-85.

82. Favre J, Jolles BM, Aissaoui R, et al. Ambulatory measurement of 3D knee joint angle. J Biomech 2008; 41(5):1029-35.

83. Picerno P, Cereatti A, Cappozzo A. Joint kinematics estimate using wearable inertial and magnetic sensing modules. Gait Posture 2008; 28(4):588-95.

84. Cutti AG, Ferrari A, Garofalo P, et al. 'Outwalk': a protocol for clinical gait analysis based on inertial and magnetic sensors. Med Biol Eng Comput 2010; 48(1):17-25.

85. O'Donoyan KJ, Kamnik R, O'Keeffe DT, et al. An inertial and magnetic sensor based technique for joint angle measurement. J Biomech 2007; 40(12):2604-11.

86. Picerno P, Cereatti A, Cappozzo A. A spot check for assessing static orientation consistency of inertial and magnetic sensing units. Gait Posture 2011; 33(3):373-8.

87. Favre J, Luthi F, Jolles BM, Siegrist O, Najafi B, Aminian K. A new ambulatory system for comparative evaluation of the three-dimensional knee kinematics, applied to anterior cruciate ligament injuries. Knee Surg Sports Traumatol Arthrosc. 2006;14(7):592-604.

88. van den Noort JC, Ferrari A, Cutti AG, et al. Gait analysis in children with cerebral palsy via inertial and magnetic sensors. Med Biol Eng Comput 2013; 51(4):377-86.

89. Rocchi L, Chiari L, Cappello A. Feature selection of stabilometric parameters based on principal component analysis. Med Biol Eng Comput 2004; 42(1):71-9. 
90. Mayagoitia RE, Lötters JC, Veltink PH, et al. Standing balance evaluation using a triaxial accelerometer. Gait Posture 2002;16(1):55-9.

91. Marchetti GF, Bellanca J, Whitney SL, et al. The development of an accelerometer-based measure of human upright static anterior-posterior postural sway under various sensory conditions: testretest reliability, scoring and preliminary validity of the Balance Accelerometry Measure (BAM) J Vestib Res 2013;23(4-5):227-35.

92. Mancini M, Salarian A, Carlson-Kuhta P, et al. ISway: a sensitive, valid and reliable measure of postural control. J Neuroeng Rehabil 2012; 9:59.

93. Kutilek P, Socha V, Cakrt O, et al. Differences in evaluation methods of trunk sway using different MoCap systems. Acta Bioeng Biomech 2014; 16(2):85-94.

94. Moe-Nilssen R, Helbostad JL. Trunk accelerometry as a measure of balance control during quiet standing. Gait Posture 2002; 16(1):60-8.

95. Martínez-Ramírez A, Lecumberri P, Gómez M, et al. Frailty assessment based on wavelet analysis during quiet standing balance test. J Biomech 2011; 44(12):2213-20.

96. Mancini M, Horak FB, Zampieri C, et al. Trunk accelerometry reveals postural instability in untreated Parkinson's disease. Parkinsonism Relat Disord 2011; 17(7):557-62.

97. Baston C, Mancini M, Schoneburg B, et al. Postural strategies assessed with inertial sensors in healthy and parkinsonian subjects. Gait Posture 2014; 40(1):70-5.

98. Mirelman A, Herman T, Nicolai S, et al. Audio-biofeedback training for posture and balance in patients with Parkinson's disease. J Neuroeng Rehabil 2011; 8:35.

99. Solomon AJ, Jacobs JV, Lomond KV, et al. Detection of postural sway abnormalities by wireless inertial sensors in minimally disabled patients with multiple sclerosis: a case-control study. $\mathrm{J}$ Neuroeng Rehabil 2015; 12:74.

100. King LA, Horak FB, Mancini M, et al. Instrumenting the balance error scoring system for use with patients reporting persistent balance problems after mild traumatic brain injury. Arch Phys Med Rehabil 2014;(2):353-9.

101. Dozza M, Chiari L, Horak FB. Audio-biofeedback improves balance in patients with bilateral vestibular loss. Arch Phys Med Rehabil 2005; 86(7):1401-3.

102. Najafi B, Aminian K, Loew F, et al. Measurement of stand-sit and sit-stand transitions using a

miniature gyroscope and its application in fall risk evaluation in the elderly. IEEE Trans Biomed Eng 2002; 49(8):843-51.

103. Zijlstra W, Bisseling RW, Schlumbohm S, et al. A body-fixed-sensor-based analysis of power during sit-to-stand movements. Gait Posture 2010; 31(2):272-8.

104. Van Lummel RC, Ainsworth E, Lindemann U, et al. Automated approach for quantifying the repeated sit-to-stand using one body fixed sensor in young and older adults. Gait Posture 2013 May; 38(1):153-6. 
105. Regterschot GR, Zhang W, Baldus H, et al. Test-retest reliability of sensor-based sit-to-stand measures in young and older adults. Gait Posture 2014; 40(1):220-4.

106. van Lummel RC, Ainsworth E, Hausdorff JM, et al. Validation of seat-off and seat-on in repeated sit-to-stand movements using a single-body-fixed sensor. Physiol Meas 2012; 33(11):185567.

107. Salarian A, Horak FB, Zampieri C, Cet al. iTUG, a sensitive and reliable measure of mobility. IEEE Trans Neural Syst Rehabil Eng 2010; 18(3):303-10.

108. Zijlstra A, Mancini M, Lindemann U, et al. Sit-stand and stand-sit transitions in older adults and patients with Parkinson's disease: event detection based on motion sensors versus force plates, $J$ Neuroeng Rehabil 2012; 9:75.

109. Zampieri C, Salarian A, Carlson-Kuhta P, et al. The instrumented timed up and go test: potential outcome measure for disease modifying therapies in Parkinson's disease. J Neurol Neurosurg Psychiatry 2010; 81(2):171-6.

110. Regterschot GR, Zhang W, Baldus H, et al. Sensor-based monitoring of sit-to-stand performance is indicative of objective and self-reported aspects of functional status in older adults. Gait Posture 2015; 41(4):935-40.

111. Mancini M, Priest KC, Nutt JG, et al. Quantifying freezing of gait in Parkinson's disease during the instrumented timed up and go test. Conf Proc IEEE Eng Med Biol Soc 2012; 2012:1198-201.

112. Coulthard JT, Treen TT, Oates AR, et al. Evaluation of an inertial sensor system for analysis of timed-up-and-go under dual-task demands. Gait Posture 2015; 41(4):882-7.

113. Mancini M, King L, Salarian A, et al. Mobility Lab to Assess Balance and Gait with Synchronized Body-worn Sensors. J Bioeng Biomed Sci 2011; Suppl 1:007.

114. Dewey DC, Miocinovic S, Bernstein I, et al. Automated gait and balance parameters diagnose and correlate with severity in Parkinson disease. J Neurol Sci 2014; 345(1-2):131-8.

115. King LA, Salarian A, Mancini M, Pet al. Exploring outcome measures for exercise intervention in people with Parkinson's disease. Parkinsons Dis 2013; 2013:572134.

116. Spain RI, St George RJ, Salarian A, et al. Body-worn motion sensors detect balance and gait deficits in people with multiple sclerosis who have normal walking speed. Gait Posture 2012; 35(4):573-8.

117. Horak F, King L, Mancini M. Role of body-worn movement monitor technology for balance and gait rehabilitation. Phys Ther 2015; 95(3):461-70.

118. Iosa M, Mazzà C, Frusciante R, et al. Mobility assessment of patients with facioscapulohumeral dystrophy. Clin Biomech. 2007;22(10):1074-82

119. Hyde RA, Ketteringham LP, Neild SA, et al. Estimation of upper-limb orientation based on accelerometer and gyroscope measurements. IEEE Trans Biomed Eng 2008; 55(2 Pt 1):746-54. 
120. El-Gohary M, McNames J. Shoulder and elbow joint angle tracking with inertial sensors. IEEE Trans Biomed Eng 2012; 59(9):2635-41.

121. Zhou H, Stone T, Hu H, et al. Use of multiple wearable inertial sensors in upper limb motion tracking. Med Eng Phys 2008; 30(1):123-33.

122. Cutti AG, Giovanardi A, Rocchi L, et al. Ambulatory measurement of shoulder and elbow kinematics through inertial and magnetic sensors. Med Biol Eng Comput 2008; 46(2):169-78.

123. Pérez R, Costa Ú, Torrent M, et al. Upper limb portable motion analysis system based on inertial technology for neurorehabilitation purposes. Sensors (Basel) 2010; 10(12):10733-51.

124. Ricci L, Formica D, Sparaci L, et al. A new calibration methodology for thorax and upper limbs motion capture in children using magneto and inertial sensors. Sensors (Basel) 2014; 14(1):1057-72.

125. Parel I, Cutti AG, Fiumana G, et al. Ambulatory measurement of the seapulohumeral rhythm: intra- and inter-operator agreement of a protocol based on inertial and magnetic sensors. Gait Posture 2012; 35(4):636-40.

126. Pellegrini A1, Tonino P, Paladini P, et al. Motion analysis assessment of alterations in the scapulo-humeral rhythm after throwing in baseball pitchers. Musculoskelet Surg 2013; 97 Suppl 1:9-13.

127. Tranquilli C, Bernetti A, Picerno P. Ambulatory joint mobility and muscle strength assessment during rehabilitation using a single wearable inertial sensor. Med Sport 2013; 66(4):583-97.

128. Picerno P, Viero V, Donati M,et al. Ambulatory assessment of shoulder abduction strength curve using a single wearable inertial sensor. J Rehabil Res Dev 2015; 52(2):171-80.

129. Kim Y, Beets MW, Welk GJ. Everything you wanted to know about selecting the "right" Actigraph accelerometer cut-points for youth, but...: a systematic review. J Sci Med Sport 2012 ;15(4):311-21.

130. Veltink PH, Bussmann HBJ, de Vries W, et al. Detection of static and dynamic activities using uniaxial accelerometers. IEEE Trans Rehab Eng 1996; 4:375-85.

131. Trost SG, Fees BS, Haar SJ, et al. Identification and validity of accelerometer cut-points for toddlers. Obesity (Silver Spring) 2012; 20(11):2317-9.

132. Freedson P, Pober D, Janz KF. Calibration of accelerometer output for children. Med Sci Sports Exerc $2005 ; 37(11$ Suppl):S523-30.

133. Kim Y, Lee JM, Peters BP, Gaesser GA, et al. Examination of different accelerometer cut-points for assessing sedentary behaviors in children. PLoS One 2014 3;9(4):e90630.

134. Matthew CE. Calibration of accelerometer output for adults. Med Sci Sports Exerc $2005 ; 37(11$ Suppl):S512-22.

135. Motl RW, Snook EM, Agiovlasitis S, et al. Calibration of accelerometer output for ambulatory adults with multiple sclerosis. Arch Phys Med Rehabil 2009 ;90(10):1778-84. 
136. Nero H, Benka Wallén M, Franzén E, et al. Accelerometer Cut Points for Physical Activity Assessment of Older Adults with Parkinson's Disease. PLoS One 2015 2;10(9):e0135899.

137. Dijkstra B, Kamsma YP, Zijlstra W. Detection of gait and postures using a miniaturized triaxial accelerometer-based system: accuracy in patients with mild to moderate Parkinson's disease. Arch Phys Med Rehabil 2010 ;91(8):1272-7.

138. Dijkstra B, Zijlstra W, Scherder E, et al. Detection of walking periods and number of steps in older adults and patients with Parkinson's disease: accuracy of a pedometer and an accelerometrybased method. Age Ageing 2008 ;37(4):436-41.

139. Godfrey A, Conway R, Meagher D, et al. Direct measurement of human movement by accelerometry. Med Eng Phys 2008 ;30(10):1364-86. ** of considerable interest

This paper presents the underlying biomechanical elements necessary to understand and study human movement using direct measurement by accelerometry.

140. Hobert MA, Maetzler W, Aminian K, et al. Technical and clinical view on ambulatory assessment in Parkinson's disease. Acta Neurol Scand $2014 ; 130(3): 139-47$.

141. Haeuber E, Shaughnessy M, Forrester LW, et al. Accelerometer monitoring of home- and community-based ambulatory activity after stroke. Arch Phys Med Rehabil 2004 ;85(12):19972001.

142. Wagenmakers R, Stevens M, Zijlstra W, et al. Habitual physical activity behavior of patients after primary total hip arthroplasty. Phys Ther 2008 ;88(9):1039-48.

143. Allet L, Knols RH, Shirato K, etal. Wearable systems for monitoring mobility-related activities in chronic disease: a systematic review. Sensors (Basel) 2010;10(10):9026-52.

144. de Bruin ED, Hartmann A, Uebelhart D, et al. Wearable systems for monitoring mobility-related activities in older people: a systematic review. Clin Rehabil 2008 ;22(10-11):878-95.

145. Cooper AR, Page A, Fox KR, et al. Physical activity patterns in normal, overweight and obese individuals using minute-by-minute accelerometry. Eur J Clin Nutr 2000 ;54(12):887-94.

146. Schwickert L, Becker C, Lindemann U, et al. Fall detection with body-worn sensors : a systematic review. Z Gerontol Geriatr 2013;46(8):706-19.

147. Heinze F, Hesels K, Breitbach-Faller N, Schmitz-Rode T, Disselhorst-Klug C. Movement analysis by accelerometry of newborns and infants for the early detection of movement disorders due to infantile cerebral palsy. Med Biol Eng Comput. 2010;48(8):765-72.

148. Zoccolillo L, Morelli D, Cincotti F, Muzzioli L, Gobbetti T, Paolucci S, Iosa M. Video-game based therapy performed by children with cerebral palsy: a cross-over randomized controlled trial and a cross-sectional quantitative measure of physical activity. Eur J Phys Rehabil Med. 2015 Feb 5.[Epub ahead of print].

149. Elble RJ, Koller WC. Tremor. Baltimore, MD: The John Hopkins University Press; 1990. 
150. Sturman MM, Vaillancourt DE, Corcos DM. Effects of aging on the regularity of physiological tremor. J Neurophysiol. 2005;93(6):3064-3074.

151. Duval C, Jones J. Assessment of the amplitude of oscillations associated with high-frequency components of physiological tremor: impact of loading and signal differentiation. Exp Brain Res. 2005;163(2):261-266.

152. Charles PD, Esper GJ, Davis TL, Maciunas RJ, Robertson D. Classification of tremor and update on treatment. Am Fam Physician. 1999;59(6):1565-1572.

153. Sandroni P, Young RR. Tremor: classification, diagnosis and management. Am Fam Physician 1994;50: 1505-1512.

154. Spyers-Ashby JM, Stokes MJ, Bain PG, Roberts SJ. Classification of normat and pathological tremors using a multidimensional electromagnetic system. Med Eng Phys. 1999;21(10):713-723.

155. Elble RJ. Gravitational artifact in accelerometric measurements of tremor. Clin Neurophysiol. 2005;116(7):1638-1643.

156. Elble RJ. Characteristics of physiologic tremor in young and elderly adults. Clin Neurophysiol. 2003;114(4):624-635.

157. Hallet M. Classification and treatment of tremor. JAMA 1991;266:1115-7.

158. Patel S, Park H, Bonato P, Chan L, Rodgers M. A review of wearable sensors and systems with application in rehabilitation. J Neuroeng Rehabil. 2012;9:21. ** of high interest

This review paper summarizes recent developments in the field of wearable sensors and systems that are relevant to the field of rehabilitation. Applications described in this review paper include those that focus on health and wellness, safety, home rehabilitation, assessment of treatment efficacy, and early detection of disorders.

159. Teixeira da Silva, JA. Negative results: negative perceptions limit their potential for increasing reproducibility. J Negat Results Biomed 2015;14:12.

160. Nishiguchi S, Yamada M, Nagai K, Mori S, Kajiwara Y, Sonoda T, Yoshimura K, Yoshitomi H, Ito H, Okamoto K, Ito T, Muto S, Ishihara T, Aoyama T. Reliability and validity of gait analysis by android-based smartphone. Telemed J E Health. 2012;18(4):292-6.

161. Nishiguchi S, Ito H, Yamada M, Yoshitomi H, Furu M, Ito T, Shinohara A, Ura T, Okamoto $\mathrm{K}$, Aoyama T. Self-assessment tool of disease activity of rheumatoid arthritis by using a smartphone application. Telemed J E Health. 2014;20(3):235-40.

162. Bonato P. Wearable sensors/systems and their impact on biomedical engineering. IEEE Eng Med Biol Mag. 2003;22(3):18-20.

163. Lundervold DA, Poppen R. Biobehavioral intervention for older adults coping with essential tremor.

Appl Psychophysiol Biofeedback. 2004;29(1):63-73. 
164. Leardini A, Lullini G, Giannini S, Berti L, Ortolani M, Caravaggi P. Validation of the angular measurements of a new inertial-measurement-unit based rehabilitation system: comparison with state-of-the-art gait analysis. J Neuroeng Rehabil. 2014;11:136.

165. Raya R, Rocon E, Gallego JA, Ceres R, Pons JL. A robust Kalman algorithm to facilitate human-computer interaction for people with cerebral palsy, using a new interface based on inertial sensors. Sensors (Basel). 2012;12(3):3049-67.

166. Raya R, Rocon E, Ceres R, Harlaar J, Geytenbeek J. Characterizing head motor disorders to create novel interfaces for people with cerebral palsy: creating an alternative communication channel by head motion. IEEE Int Conf Rehabil Robot. 2011;2011:5975409.

167. Iosa M, Morone G, Fusco A, et al. Seven capital devices for the future of stroke rehabilitation. Stroke Res Treat. 2012;2012:187965. 


\section{Table 1. Clinical applications of IMUs.}

In this table, type of sensor (more than of device) for gathering the desired information are reported (e,g, if a MIMU was used for collecting triaxial accelerations, then "type" will be simply referred to as "accelerometer"). IMU = inertial measurement unit; MIMU = magnetic and inertial measurement unit; FES = functional electrical stimulation; $T U G=$ timed up-and-go test; SLAP $=$ superior labrum anterior to posterior lesion

\begin{tabular}{|c|c|c|c|c|c|c|}
\hline \multirow[t]{2}{*}{ Study } & \multirow{2}{*}{$\begin{array}{l}\text { Number } \\
\text { and type } \\
\text { of } \\
\text { sensors }\end{array}$} & \multirow[t]{2}{*}{$\begin{array}{l}\text { Sensor } \\
\text { placement }\end{array}$} & \multirow[t]{2}{*}{ Aim and main outcomes } & \multicolumn{2}{|c|}{$\begin{array}{l}\text { Number of } \\
\text { subjects }\end{array}$} & \multirow[t]{2}{*}{ Type of pathology } \\
\hline & & & & healthy & patients & \\
\hline \multicolumn{7}{|c|}{ Upright gait stability } \\
\hline $\begin{array}{l}\text { Mizuike et } \\
\text { al. } 2009 \\
{[27]}\end{array}$ & $\begin{array}{l}1 \text { triaxial } \\
\text { accelero } \\
\text { meter }\end{array}$ & $\begin{array}{l}\text { low back at the } \\
\text { level of L3 }\end{array}$ & $\begin{array}{l}\text { Assess the upright gait stability of } \\
\text { patients with stroke by } \\
\text { accelerations (RMS and } \\
\text { autocorrelation) }\end{array}$ & & 63 & Stroke \\
\hline $\begin{array}{l}\text { Iosa et al. } \\
2012[28]\end{array}$ & $\begin{array}{l}1 \text { triaxial } \\
\text { accelero } \\
\text { meter }\end{array}$ & $\begin{array}{l}\text { low back at the } \\
\text { level of L3 }\end{array}$ & $\begin{array}{l}\text { Analysis of upright gait stability on } \\
\text { children with cerebral palsy (RMS, } \\
\text { HR) }\end{array}$ & 17 & 17 & $\begin{array}{l}\text { Children with } \\
\text { Cerebral Palsy }\end{array}$ \\
\hline $\begin{array}{l}\text { Iosa et al. } \\
2012[32]\end{array}$ & $\begin{array}{l}1 \text { triaxial } \\
\text { accelero } \\
\text { meter }\end{array}$ & $\begin{array}{l}\text { low back at the } \\
\text { level of L3 }\end{array}$ & $\begin{array}{l}\text { Assessment of upper-body } \\
\text { dynamic stability during walking } \\
\text { in patients with subacute stroke } \\
\text { (RMS, HR) }\end{array}$ & 30 & 15 & Stroke \\
\hline $\begin{array}{l}\text { Moe- } \\
\text { Nilssen \& } \\
\text { Helbostad } \\
2005[33]\end{array}$ & $\begin{array}{l}1 \text { triaxial } \\
\text { accelero } \\
\text { meter }\end{array}$ & $\begin{array}{l}\text { low back at the } \\
\text { level of L3 }\end{array}$ & $\begin{array}{l}\text { Spatio-temporal gait parameters, } \\
\text { autocorrelation and variability }\end{array}$ & 64 & 0 & $\begin{array}{l}\text { Not pathology but } \\
\text { frail elderly (32) and } \\
\text { fit elderly (32) }\end{array}$ \\
\hline $\begin{array}{l}\text { Iosa et al. } \\
2012[41]\end{array}$ & $\begin{array}{l}1 \text { triaxial } \\
\text { accelero } \\
\text { meter }\end{array}$ & $\begin{array}{l}\text { low back at the } \\
\text { level of L3 }\end{array}$ & $\begin{array}{l}\text { Assess the effects of visual } \\
\text { deprivation on gait dynamic } \\
\text { stability (RMS) }\end{array}$ & 28 & 0 & - \\
\hline $\begin{array}{l}\text { Iosa et al. } \\
2012[42]\end{array}$ & $\begin{array}{l}1 \text { triaxial } \\
\text { accelero } \\
\text { meter }\end{array}$ & $\begin{array}{l}\text { low back at the } \\
\text { level of } \mathrm{L} 3\end{array}$ & $\begin{array}{l}\text { Effects of walking endurance } \\
\text { reduction on gait stability in } \\
\text { patients with stroke. (RMS) }\end{array}$ & 10 & 20 & Stroke \\
\hline $\begin{array}{l}\text { Iosa et al. } \\
2013[43]\end{array}$ & $\begin{array}{l}1 \text { triaxial } \\
\text { accelero } \\
\text { meter }\end{array}$ & $\begin{array}{l}\text { low back at the } \\
\text { level of } \mathrm{L} 3\end{array}$ & $\begin{array}{l}\text { Analysis of walking and running } \\
\text { stability on children with cerebral } \\
\text { palsy (RMS, HR) }\end{array}$ & 20 & 20 & $\begin{array}{l}\text { Children with } \\
\text { Cerebral Palsy }\end{array}$ \\
\hline $\begin{array}{l}\text { Henchoz et } \\
\text { al. } 2015 \\
{[44]}\end{array}$ & & $\begin{array}{l}\text { an IMU on low } \\
\text { back at the level } \\
\text { of L3, an IMU } \\
\text { on left foot }\end{array}$ & $\begin{array}{l}\text { Spatiotemporal parameters of } \\
\text { walking }\end{array}$ & 13 & 13 & $\begin{array}{l}\text { Men with low back } \\
\text { pain }\end{array}$ \\
\hline & $\begin{array}{l}1 \text { triaxial } \\
\text { accelero } \\
\text { meter }\end{array}$ & $\begin{array}{l}\text { low back at the } \\
\text { level of L3 }\end{array}$ & $\begin{array}{l}\text { Assessment of gait stability and } \\
\text { variability in dual tasking of } \\
\text { cognitively frail people (spatio- } \\
\text { temporal parameters, stochastic } \\
\text { dynamic measures, local stability } \\
\text { exponents) }\end{array}$ & 13 & 13 & Cognitive impairment \\
\hline $\begin{array}{l}\text { Iosa et al. } \\
2014[46]\end{array}$ & $\begin{array}{l}1 \text { triaxial } \\
\text { accelero } \\
\text { meter }\end{array}$ & $\begin{array}{l}\text { low back at the } \\
\text { level of L3 }\end{array}$ & $\begin{array}{l}\text { Assessment of upright stability in } \\
\text { young adults with intellectual } \\
\text { disabilities while walking, running, } \\
\text { and dual-task running (RMS) }\end{array}$ & 7 & 18 & $\begin{array}{l}7 \text { Down Syndrome, } \\
4 \text { Autism, } \\
7 \text { Pervasive } \\
\text { developmental } \\
\text { disorders }\end{array}$ \\
\hline $\begin{array}{l}\text { Iosa et al. } \\
2014[47]\end{array}$ & $\begin{array}{l}1 \text { triaxial } \\
\text { accelero } \\
\text { meter }\end{array}$ & $\begin{array}{l}\text { low back at the } \\
\text { level of L3 }\end{array}$ & $\begin{array}{l}\text { Assessment of gait stability, } \\
\text { harmony, and symmetry (RMS, } \\
\text { HR, Simmetry Index) }\end{array}$ & 22 & 22 & $\begin{array}{l}\text { Lower-limb } \\
\text { amputation using } \\
\text { prosthesis }\end{array}$ \\
\hline Menz et al. & 2 triaxial & 1 on head & Aging and assessment of upright & 60 & 0 & Not pathology but \\
\hline
\end{tabular}




\begin{tabular}{|c|c|c|c|c|c|c|}
\hline 2003 [48] & $\begin{array}{l}\text { accelero } \\
\text { meters }\end{array}$ & $\begin{array}{l}1 \text { at low back at } \\
\text { the level of } \mathrm{S} 1\end{array}$ & $\begin{array}{l}\text { gait stability (spatio-temporal } \\
\text { parameter, RMS, HR) }\end{array}$ & & & aging $(n=30)$ \\
\hline $\begin{array}{l}\text { Senden et } \\
\text { al. } 2012 \\
{[49]}\end{array}$ & $\begin{array}{l}1 \text { triaxial } \\
\text { accelero } \\
\text { meter }\end{array}$ & $\begin{array}{l}\text { low back at the } \\
\text { level of S1 }\end{array}$ & $\begin{array}{l}\text { Assessment of dynamic balance } \\
\text { and risk of fall (spatio-temporal } \\
\text { gait parameters, RMS, HR, inter- } \\
\text { stride amplitude variability). }\end{array}$ & 50 & 50 & $\begin{array}{l}\text { Elderly with balance } \\
\text { impairment }\end{array}$ \\
\hline $\begin{array}{l}\text { Doi et al. } \\
2013[50]\end{array}$ & $\begin{array}{l}2 \text { triaxial } \\
\text { accelero } \\
\text { meters }\end{array}$ & $\begin{array}{l}1 \text { on } \mathrm{C} 7 \\
1 \text { on } \mathrm{L} 3\end{array}$ & $\begin{array}{l}\text { Assessment of } \mathrm{HR} \text { as predictor of } \\
\text { fall risk }\end{array}$ & 73 & 0 & $\begin{array}{l}\text { Not pathology but } \\
\text { fallers (16) and not- } \\
\text { fallers }(57)\end{array}$ \\
\hline & & & & & & $/ n$ \\
\hline \multicolumn{7}{|c|}{ Spatio-temporal gait parameters } \\
\hline $\begin{array}{l}\text { Moore et al. } \\
2007 \text { [59] }\end{array}$ & $1 \mathrm{IMU}$ & shank & Stride length & 10 & 7 & Parkinson's Disease \\
\hline $\begin{array}{l}\text { Willemsen } \\
\text { et al. } 1990 \\
\text { [69] }\end{array}$ & $\begin{array}{l}2 \text { biaxial } \\
\text { accelero } \\
\text { meters }\end{array}$ & shank & stance-swing detection for FES & 0 & 4 & Hemiplegic \\
\hline $\begin{array}{l}\text { Jasiewicz et } \\
\text { al. } 2006 \\
{[70]}\end{array}$ & $1 \mathrm{IMU}$ & shank or foot & gait event detection & 26 & 15 & $\begin{array}{l}14 \text { spinal cord injury } \\
1 \text { Charcot-Marie- } \\
\text { Tooth syndrome }\end{array}$ \\
\hline $\begin{array}{l}\text { de Bruin et } \\
\text { al. } 2012 \\
{[71]}\end{array}$ & $\begin{array}{l}1 \text { triaxial } \\
\text { accelero } \\
\text { meter }\end{array}$ & $\begin{array}{l}\text { low back at the } \\
\text { level of } L 2\end{array}$ & $\begin{array}{l}\text { walking speed, cadence, } \mathrm{n} \\
\text { duration and length }\end{array}$ & 0 & 29 & Diabetes (type II) \\
\hline $\begin{array}{l}\text { van den } \\
\text { Akker- } \\
\text { Scheek et } \\
\text { al. 2007 } \\
\text { [72] }\end{array}$ & $\begin{array}{l}1 \text { triaxial } \\
\text { accelero } \\
\text { meter }\end{array}$ & $\begin{array}{l}\text { lower back } \\
\text { spine }\end{array}$ & $\begin{array}{l}\text { walking speed, } \\
\text { duration }\end{array}$ & 0 & 63 & Total hip arthoplasty \\
\hline $\begin{array}{l}\text { Salarian et } \\
\text { al. } 2004 \\
\text { [73] }\end{array}$ & $\begin{array}{l}4 \\
\text { uniaxial } \\
\text { gyroscop } \\
\text { es }\end{array}$ & $\begin{array}{l}\text { thigh and } \\
\text { shank, both } \\
\text { sides }\end{array}$ & spatio-temporal parameters of gait & 10 & 10 & Parkinson's Disease \\
\hline $\begin{array}{l}\text { Aminian et } \\
\text { al. [74] }\end{array}$ & $\begin{array}{l}4 \\
\text { uniaxial } \\
\text { gyroscop } \\
\text { es }\end{array}$ & $\begin{array}{l}\text { thigh and } \\
\text { shank, both } \\
\text { sides }\end{array}$ & spatio-temporal parameters of gait & 9 & 19 & $\begin{array}{l}11 \text { unilateral } \\
\text { coxarthrosis } \\
8 \text { unilateral total hip } \\
\text { prosthesis }\end{array}$ \\
\hline $\begin{array}{l}\text { Patterson et } \\
\text { al. } 2014 \\
{[75]}\end{array}$ & $\begin{array}{l}2 \\
\text { uniaxial } \\
\text { gyroscop } \\
\text { es }\end{array}$ & shar & temporal parameters of gait cycle & 17 & 14 & $\begin{array}{l}\text { anterior cruciate } \\
\text { ligament } \\
\text { recontruction }\end{array}$ \\
\hline \multicolumn{7}{|c|}{ Joint kinematics } \\
\hline $\begin{array}{l}\text { Favre e t al. } \\
2006 \text { [87] }\end{array}$ & $\begin{array}{l}2 \text { triaxial } \\
\text { gyroscop } \\
\text { es }\end{array}$ & thigh and shank & 3D knee angular kinematics & 6 & 6 & ACL reconstruction \\
\hline $\begin{array}{l}\text { van den } \\
\text { Noort et al. } \\
2013[88]\end{array}$ & MIMUs & $\begin{array}{l}\text { pelvis, thigh, } \\
\text { snah and foot } \\
\text { (both sides) }\end{array}$ & 3D joint angular kinematics & 0 & 10 & $\begin{array}{l}\text { children with celebral } \\
\text { palsy }\end{array}$ \\
\hline \multicolumn{7}{|c|}{ Stabilometry } \\
\hline $\begin{array}{l}\text { Martínez- } \\
\text { Ramírez et } \\
\text { al. 2011 } \\
{[95]}\end{array}$ & 1/MIMU & $\begin{array}{l}\text { low back at the } \\
\text { level of L3 }\end{array}$ & $\begin{array}{l}\text { sway assessment from sway path } \\
\text { and frequency-domain signal } \\
\text { analysis }\end{array}$ & 24 & 32 & $\begin{array}{l}14 \text { frail elderly } \\
18 \text { pre-frail elderly }\end{array}$ \\
\hline $\begin{array}{l}\text { Mancini et } \\
\text { al. } 2011 \\
{[96]}\end{array}$ & $\begin{array}{l}1 \text { triaxial } \\
\text { accelero } \\
\text { meter }\end{array}$ & $\begin{array}{l}\text { low back at the } \\
\text { level of L5 }\end{array}$ & sway path analysis & 12 & 13 & Parkinson's Disease \\
\hline $\begin{array}{l}\text { Baston et al. } \\
2014 \text { [97] }\end{array}$ & $\begin{array}{l}2 \text { triaxial } \\
\text { accelero } \\
\text { meters }\end{array}$ & $\begin{array}{l}\text { low back at the } \\
\text { level of L5 and } \\
\text { shank }\end{array}$ & $\begin{array}{l}\text { sway assessment (RMS); trunk and } \\
\text { shank signals phase coordination }\end{array}$ & 7 & 12 & $\begin{array}{l}5 \text { Parkinson's } \\
\text { Disease; } \\
7 \text { Progressive } \\
\text { Supranuclear Palsy } \\
\end{array}$ \\
\hline $\begin{array}{l}\text { Mirelman et } \\
\text { al. 2011 } \\
{[98]}\end{array}$ & $\begin{array}{l}1 \text { triaxial } \\
\text { accelero } \\
\text { meter }\end{array}$ & $\begin{array}{l}\text { at the level of } \\
\text { L2-L5 }\end{array}$ & $\begin{array}{l}\text { standing balance training with } \\
\text { audio biofeedback based on sway } \\
\text { path }\end{array}$ & 0 & 7 & Parkinson's Disease \\
\hline
\end{tabular}




\begin{tabular}{|c|c|c|c|c|c|c|}
\hline $\begin{array}{l}\text { Solomon et } \\
\text { al. } 2015 \\
\text { [99] }\end{array}$ & $\begin{array}{l}1 \text { triaxial } \\
\text { accelero } \\
\text { meter }\end{array}$ & $\begin{array}{l}\text { low back at the } \\
\text { level of L5 }\end{array}$ & sway path analysis & 20 & 20 & multiple sclerosis \\
\hline $\begin{array}{l}\text { King et al. } \\
2014 \text { [100] }\end{array}$ & $\begin{array}{l}1 \text { triaxial } \\
\text { accelero } \\
\text { meter }\end{array}$ & $\begin{array}{l}\text { low back at the } \\
\text { level of L5 }\end{array}$ & balance error scoring system & 13 & 13 & $\begin{array}{l}\text { mild traumatic brain } \\
\text { injury }\end{array}$ \\
\hline $\begin{array}{l}\text { Dozza et al. } \\
2005[101]\end{array}$ & $\begin{array}{l}1 \text { biaxial } \\
\text { accelero } \\
\text { meter }\end{array}$ & $\begin{array}{l}\text { low back at the } \\
\text { level of L5 }\end{array}$ & sway path analysis & 9 & 9 & $\begin{array}{l}\text { bilateral loss of } \\
\text { vestibular function }\end{array}$ \\
\hline \multicolumn{7}{|c|}{ Instrumented clinical tests } \\
\hline $\begin{array}{l}\text { Zijlstra et } \\
\text { al. } 2012 \\
{[108]}\end{array}$ & $1 \mathrm{IMU}$ & $\begin{array}{l}\text { low back at the } \\
\text { level of L2-L4 }\end{array}$ & TUG timing & 12 & 10 & Parkinson's Disease \\
\hline $\begin{array}{l}\text { Zampieri et } \\
\text { al. 2010 } \\
\text { [109] }\end{array}$ & $\begin{array}{l}2 \\
\text { uniaxial } \\
\text { and } 2 \\
\text { biaxial } \\
\text { gyroscop } \\
\text { es, 1 } \\
\text { IMU } \\
\end{array}$ & $\begin{array}{l}\text { shank and wrist } \\
\text { (both sides), } \\
\text { sternum }\end{array}$ & TUG metrics & 12 & & on's Disease \\
\hline $\begin{array}{l}\text { Regterschot } \\
\text { et al. } 2015 \\
{[110]}\end{array}$ & $1 \mathrm{MIMU}$ & hip or sternum & $\begin{array}{l}\text { TUG timing and chair raising } \\
\text { muscle strength assessment }\end{array}$ & & 36 & older adults \\
\hline $\begin{array}{l}\text { Mancini et } \\
\text { al. } 2015 \\
{[111]}\end{array}$ & 3 IMUs & $\begin{array}{l}\text { lower back and } \\
\text { shank (both } \\
\text { sides) }\end{array}$ & TUG metrics & 21 & 48 & $\begin{array}{l}\text { Parkinson's Disease } \\
21 \text { freezers } \\
27 \text { non-freezers }\end{array}$ \\
\hline $\begin{array}{l}\text { Dewey et al. } \\
2014 \text { [114] }\end{array}$ & 6 IMUs & $\begin{array}{l}\text { low back, } \\
\text { sternum, wrist } \\
\text { and shank } \\
\text { (both sides) }\end{array}$ & $\begin{array}{l}\text { sway path, TUG metrics and } \\
\text { spatio-temporal parameters of gait } \\
\text { during TUG }\end{array}$ & 66 & 135 & Parkinson's Disease \\
\hline $\begin{array}{l}\text { King et al. } \\
2013 \text { [115] }\end{array}$ & 6 IMUs & $\begin{array}{l}\text { low back, } \\
\text { sternum, wrist } \\
\text { and shank } \\
\text { (both sides) }\end{array}$ & $\begin{array}{l}\text { sway path, TUG metrics and } \\
\text { spatio-temporal parameters of gait } \\
\text { during TUG }\end{array}$ & 0 & 39 & Parkinson's Disease \\
\hline $\begin{array}{l}\text { Spain et al. } \\
2012[116]\end{array}$ & 6 IMUs & $\begin{array}{l}\text { low back, } \\
\text { sternum, wrist } \\
\text { and shank } \\
\text { (both sides) }\end{array}$ & TUG metrics & 28 & 31 & Multiple sclerosis \\
\hline $\begin{array}{l}\text { Pellegrini et } \\
\text { al. 2013 } \\
{[126]}\end{array}$ & $\begin{array}{l}4 \\
\text { MIN }\end{array}$ & $\begin{array}{l}\text { scapula, } \\
\text { sternum, upper } \\
\text { arm and } \\
\text { forearm }\end{array}$ & Scapulo-humeral rhythm & 0 & 13 & $\begin{array}{l}\text { Scapulo-humeral } \\
\text { rhythm alteration }\end{array}$ \\
\hline $\begin{array}{l}\text { Tranquilli et } \\
\text { al. } 2013 \\
{[127]}\end{array}$ & $1 / 1$ & upper arm & $\begin{array}{l}\text { shoulder abduction mobility and } \\
\text { strength }\end{array}$ & 0 & 1 & Shoulder slap \\
\hline \multicolumn{7}{|c|}{ Daily life activity assessment } \\
\hline $\begin{array}{l}\text { Dijkstra et } \\
\text { al. } 2010 \\
\text { [137] }\end{array}$ & $\begin{array}{l}1 \text { triaxial } \\
\text { accelerom } \\
\text { eter }\end{array}$ & $\begin{array}{l}\text { low back at the } \\
\text { level of L2 }\end{array}$ & activity classification & 0 & 20 & older people \\
\hline $\begin{array}{l}\text { Haeuber et } \\
\text { al. } 2004 \\
{[141]}\end{array}$ & $\begin{array}{l}1 \text { accelero } \\
\text { meter }\end{array}$ & Hip level & $\begin{array}{l}\text { Assessment of home and } \\
\text { community based activity in stroke }\end{array}$ & - & 17 & Stroke \\
\hline $\begin{array}{l}\text { Allet et al. } \\
2010[143] \\
\text { (review) }\end{array}$ & $\begin{array}{l}1 \text { uniaxial } \\
\text { accelerom } \\
\text { eter }\end{array}$ & waist or ankle & amount and intensity of activity & $\mathrm{n} / \mathrm{a}$ & $\mathrm{n} / \mathrm{a}$ & chronic disease \\
\hline $\begin{array}{l}\text { Cooper et } \\
\text { al. } 2000 \\
{[145]}\end{array}$ & $\begin{array}{l}1 \text { uniaxial } \\
\text { accelerom } \\
\text { eter }\end{array}$ & left hip & activity amount and intensity & 84 & 0 & $\begin{array}{l}\text { Not pathology, but } \\
\text { overweight }(n=31) \text { or } \\
\text { obese }(n=12)\end{array}$ \\
\hline $\begin{array}{l}\text { Heinze et al. } \\
2010 \text { [147] }\end{array}$ & $\begin{array}{l}4 \\
\text { accelerom } \\
\text { eters }\end{array}$ & $\begin{array}{l}\text { Forearms and } \\
\text { feet }\end{array}$ & $\begin{array}{l}\text { Monitoring activities in pre-term } \\
\text { newborns for assessing risk of } \\
\text { cerebral palsy }\end{array}$ & 19 & 4 & Pre-term newborns \\
\hline
\end{tabular}




\begin{tabular}{|c|c|c|c|c|c|c|}
\hline $\begin{array}{l}\text { Zoccolillo } \\
\text { et al. } 2015 \\
{[148]}\end{array}$ & $5 \mathrm{IMU}$ & $\begin{array}{l}\text { Low trunk, } \\
\text { limbs }\end{array}$ & $\begin{array}{l}\text { Monitoring activities during video- } \\
\text { game based therapy vs. } \\
\text { conventional physiotherapy }\end{array}$ & 0 & 8 & Cerebral palsy \\
\hline \multicolumn{7}{|c|}{ Tremor assessment } \\
\hline $\begin{array}{l}\text { Elble } 2003 \\
{[156]}\end{array}$ & $\begin{array}{l}1 \text { triaxial } \\
\text { accelero } \\
\text { meter }\end{array}$ & Dorsum of hand & $\begin{array}{l}\text { To determine the prevalence of } \\
\text { tremor-related motor-unit } \\
\text { entrainment in young and elderly } \\
\text { adults using accelerometry and } \\
\text { electromyography. }\end{array}$ & 200 & 0 & Aging \\
\hline
\end{tabular}




\section{Figure Legends}

\section{Figure 1. Trunk Acceleration during gait}

Trunk antero-posterior acceleration recorded during the central 5 seconds of 10 meter walking test. From above to below, the data are of: a healthy adult (46 years old), a child with typical development (2 years old), a healthy elderly (79 years old), a patient with stroke (51 years old), a child with cerebral palsy (4 years old), a boy with Down syndrome (15 years old), a boy with autism (13 years old), and a patient with lower limb amputation walking with a prothesis (55 years old).

\section{Trunk antero-posterior acceleration}
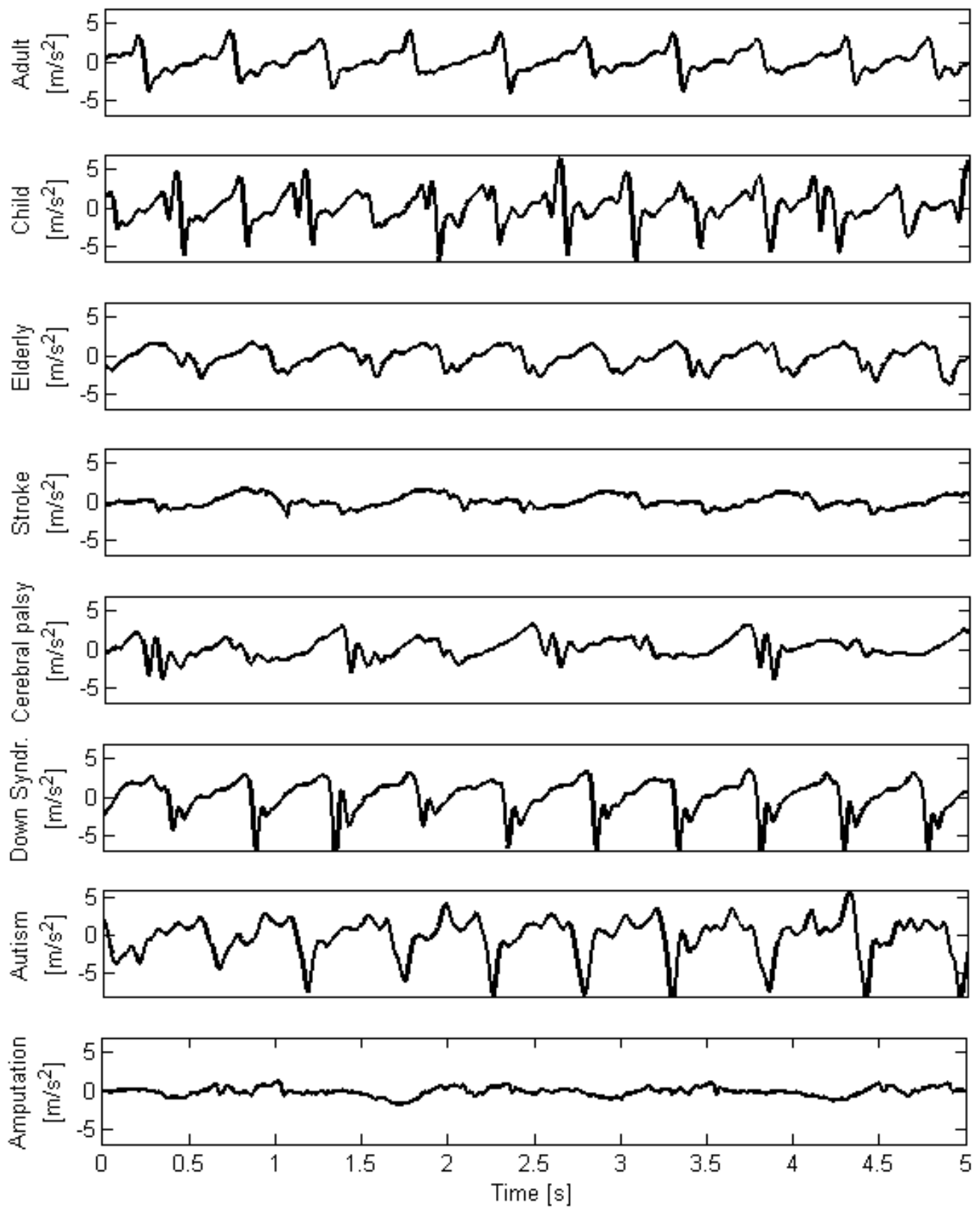
Figure 2. Trunk Acceleration and angular speed during TUG

Raw data of trunk antero-posterior acceleration (above) and trunk angular velocity around craniocaudal axis (below) are shown for a subject with stroke performing the Timed-up and go test. The phases of TUG are clearly identifiable (stand-up, walking, turning around the target, walking, turning in place and sitting down).
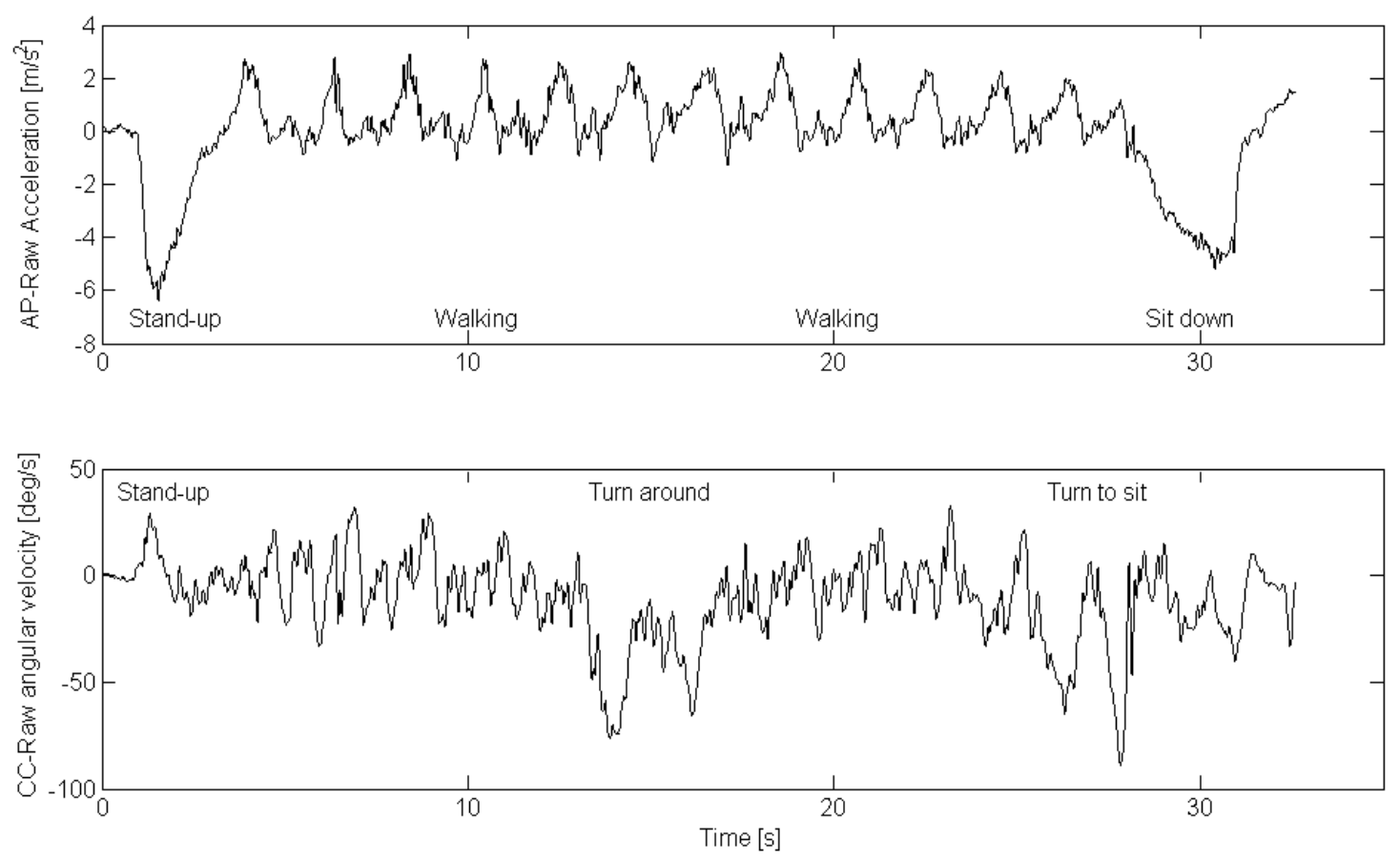
Figure 3. Hand acceleration for tremor assessment.

Hand dorso-ventral acceleration of a healthy subject (35 years old, above) and a patient with Parkinson's disease (77 years old, below) with (on the left) and without (on the right) a $1 \mathrm{~kg}$ load fixed around the wrist. For the patients, the wide sinusoidal vibration has been clearly identifiable, and it has been partially reduced with the load.
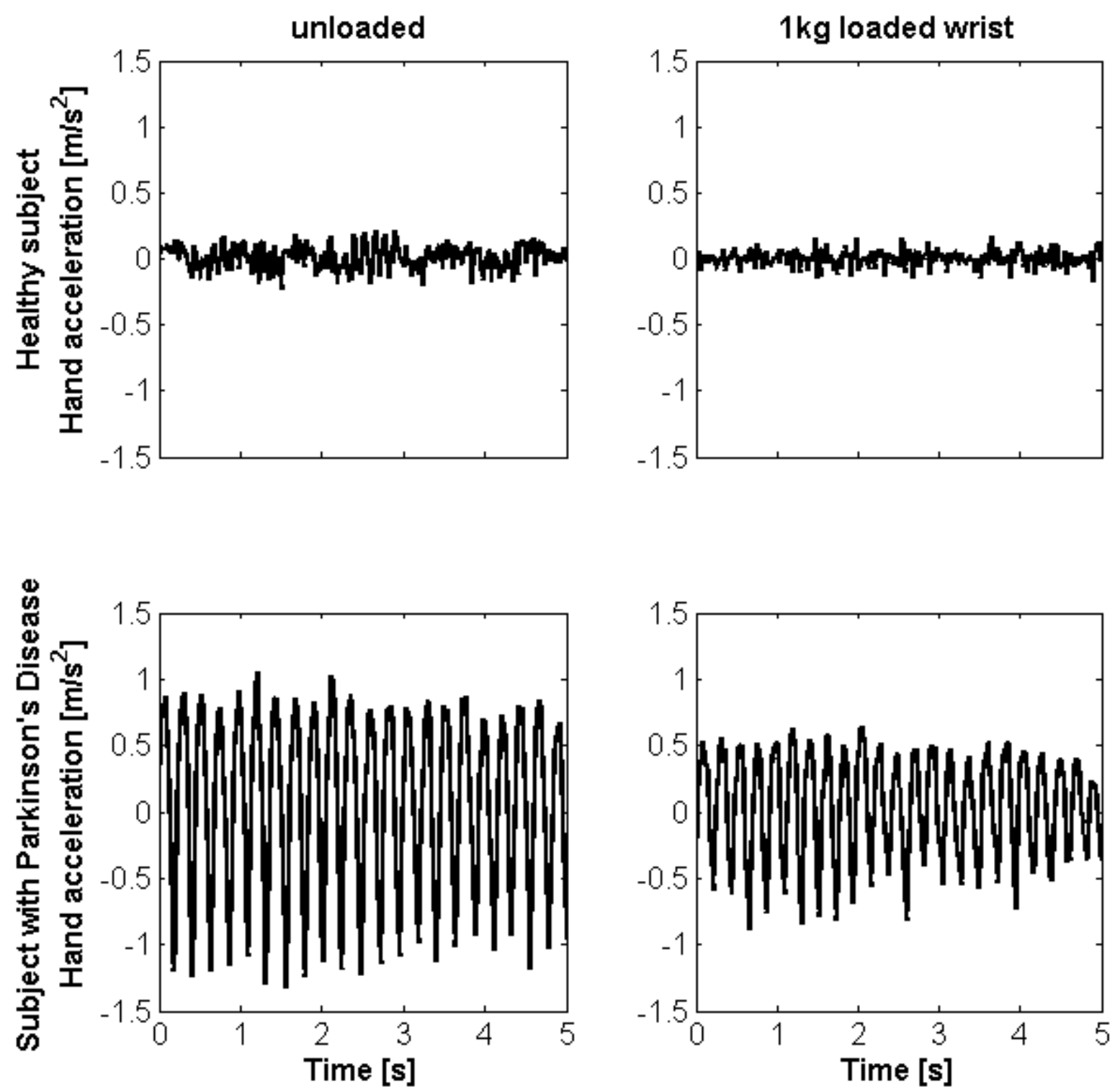
Figure 4. A system for rehabilitation embedding IMUs

Riablo $^{T M}$, a system for video-game based therapy controlled by 5 (or less) IMUs. On the left a configuration for upper extremities rehabilitation (alternatively, IMUs can also be located on lower extremities), on the right a patient during the rehabilitation in the Private Inpatient Unit of our Foundation: shoulder abduction with the flexed elbow moves up the spaceship on the screen allowing the required passage in the rings.
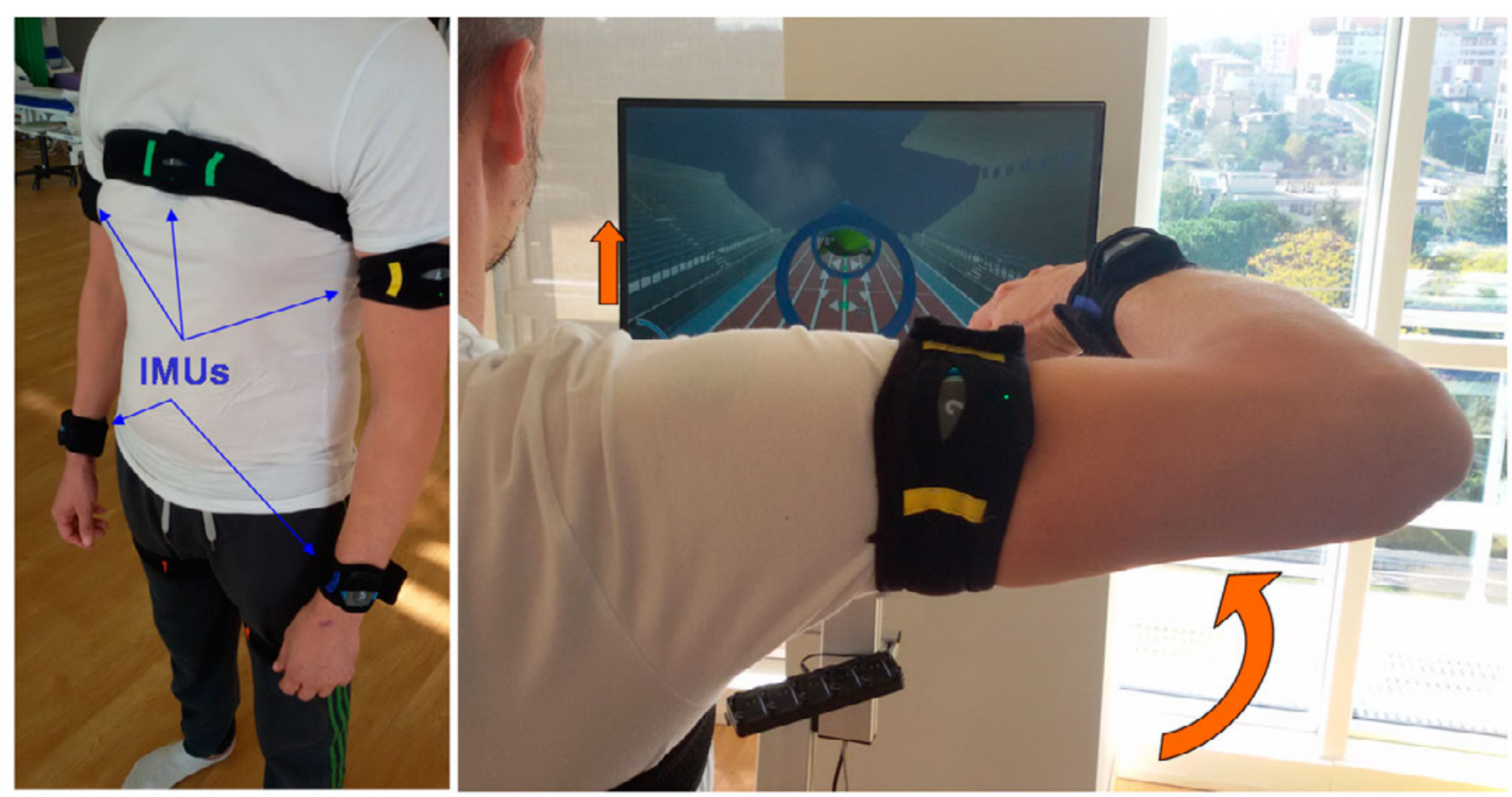